The Version of Record of this mansucript has been published and it is available in Journal: Powder Metallurgy

Published online: 24 Sep 2019

https://www.tandfonline.com/,

DOI: https://doi.org/10.1080/00325899.2019.1669299 


\section{A review on recent developments in binder jetting metal additive manufacturing: materials and process characteristics}

\section{Asier Lores, Naiara Azurmendi, Iñigo Agote \& Ester Zuza}

To cite this article: Asier Lores, Naiara Azurmendi, Iñigo Agote \& Ester Zuza (2019): A review on recent developments in binder jetting metal additive manufacturing: materials and process characteristics, Powder Metallurgy

To link to this article: https://doi.org/10.1080/00325899.2019.1669299

曲 Published online: 24 Sep 2019.

Submit your article to this journal $\pi$

Q View related articles $\llbracket$

View Crossmark data ¿ 


\title{
A review on recent developments in binder jetting metal additive manufacturing: materials and process characteristics
}

\author{
Asier Lores $\mathbb{D}^{\mathrm{a}}$, Naiara Azurmendi ${ }^{\mathrm{a}}$, Iñigo Agote $\mathbb{D}^{\mathrm{a}}$ and Ester Zuza $\mathbb{D}^{\mathrm{b}}$ \\ ${ }^{\mathrm{a} F u n d a c i o ́ n ~ T e c n a l i a ~ R e s e a r c h ~ \& ~ I n n o v a t i o n, ~ D o n o s t i a ~ / ~ S a n ~ S e b a s t i a n, ~ S p a i n ; ~}{ }^{\mathrm{b}}$ Department of Mining and metallurgical engineering and \\ materials science, Engineering school of Bilbao, UPV/EHU, Bilbao, Spain
}

\begin{abstract}
Binder Jetting Metal Additive Manufacturing (BJ-MAM), known also as metal 3D-printing, is a powder bed-based additive manufacturing technology. It consists of the deposition of liquid binder droplets to selectively join powder particles to enable the creation of near-net shaped parts, which subsequently are consolidated via sintering process. This technology is known for its capability to process a wide range of different materials and for its orientation towards large volume production series. Binder Jetting has recently been drawing the attention of both the research sphere as well as several industrial sectors. The present review study encompasses the various and most remarkable aspects of BJ-MAM part fabrication. The review covers the material selection and characterisation considerations, followed by the manufacturing process features and the parameter effect on different part properties. It concludes with an overview concerning the most recent case studies with regards to diverse metal alloy developments.
\end{abstract}

\section{ARTICLE HISTORY}

Received 19 February 2019

Accepted 14 September 2019

\section{KEYWORDS}

Binder Jetting; additive manufacturing; powder metallurgy; metal alloy; process parameter effect

\section{Highlights}

- State of the art of the most recent studies and developments in Binder Jetting (BJ) metal additive manufacturing (MAM).

- Critical overview of BJ process parameters and their effect on part properties.

- Considerations about powder characterisation and technology usage

\section{Introduction}

Additive manufacturing (AM) was born in the 1980s providing a new scope for Rapid Prototyping and Tooling (RP\&T) developments. The first AM machine, known as the Stereolithography Apparatus, was created in 1984 and patented in 1986 [1] by Charles W. Hull of 3-D Systems Corporation, although some claim that the first AM patent was proposed by Baker in early twenties as an ancient electric-arc-based metal deposition technology [2]. AM was further developed and extensively used for RP\&T purposes, enabling shorter product development cycles [3] due to reduced costs, lead times and human interactions [4]. AM is, in fact, defined as 'a process of joining materials to make objects from 3D model data, usually layer upon layer, as opposed to subtractive manufacturing methodologies', according to ASTM standard F2792-12a [5]. This standard also divides existing AM processes into seven groups, providing a standardised guideline with the aim of being a reference for education or communication purposes. Most common technologies for metal additive manufacturing (MAM) are shown in Figure 1, according to previously mentioned ASTM standard classification.

One of the most remarkable benefits of AM technologies is its complex shaped part production capability. Due to its material layer-to-layer building process, AM enables new design features that are impossible to achieve with traditional subtractive routes. For example, high complexity cooling channels or topologically optimised lightweight structures [6]. In other terms, AM enables designs without the constraints of the traditional manufacturing processes, enabling a design-driven manufacturing future [7]. This, in fact, permits the optimisation of assembly designs, thereby significantly reducing the part count and final assembly weight [8]. For those reasons, AM has been successfully integrated into the aerospace [9] and medical [10] sectors, where a high customisation capability and design freedom are required.

Despite all the benefits that it can provide, MAM still must deal with some obstacles to be able to ensure a rapid growth and to consolidate its industrial integration. Some of these are restrictions related to part sizes and production times, along with high equipment and raw material costs. In addition, the role played by new regulations could lead to certain social and commercial concerns regarding the long-term uptake of AM-based processes [11]. 


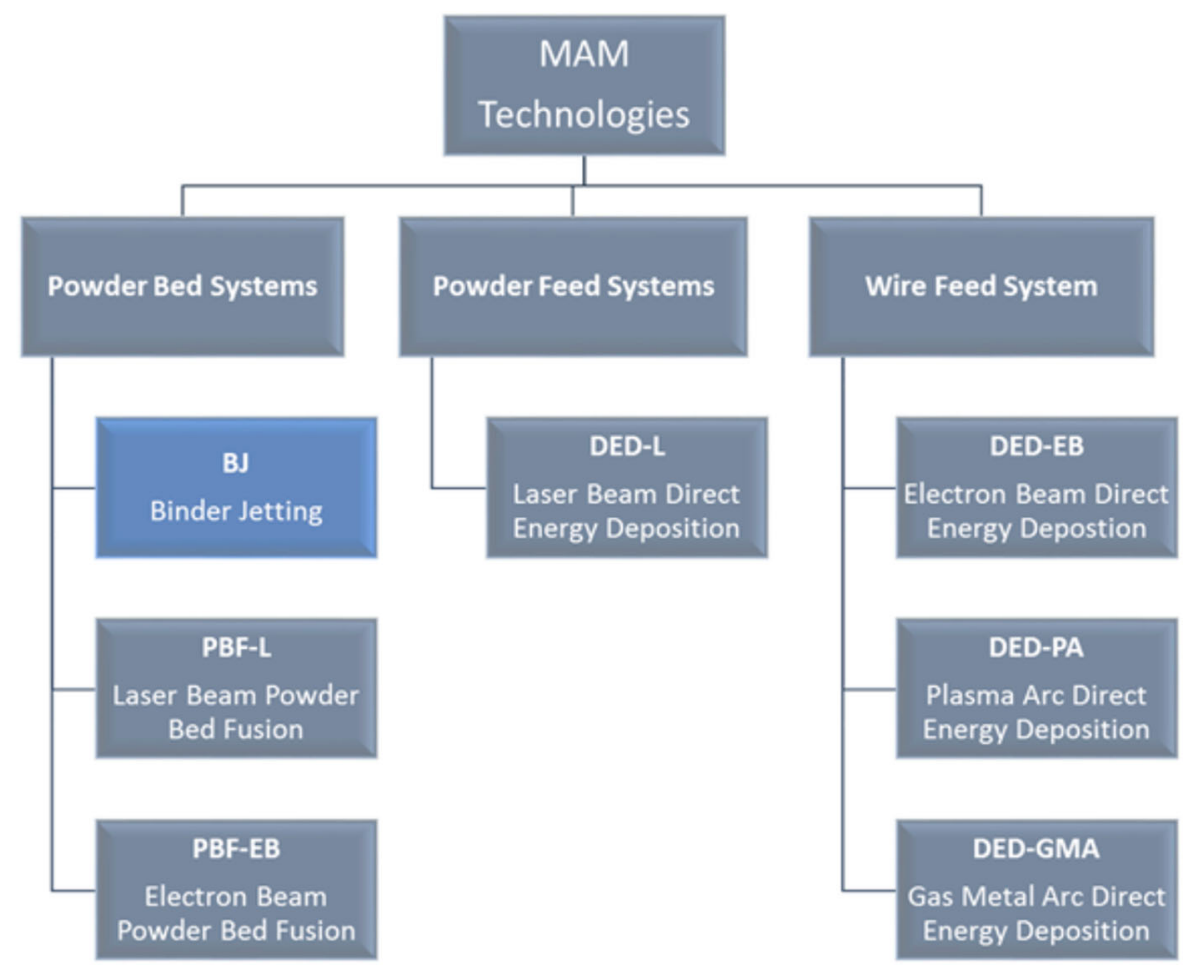

Figure 1. MAM technologies classification according to ASTM standard [5].

Binder Jetting (BJ), originally named 'Three-dimensional printing technique', was invented and patented by MIT in the early 1990s [12]. The general BJ process chain is shown in Figure 2. To this day, this technology has been mainly used to fabricate sand moulds and cores for the metal casting industry. As a direct MAM technology, BJ has more attracted attention over the last few years, mainly thanks to its high productivity and the relative simplicity of its integration within powder metallurgy industry. As it is a sinterbased AM technology, a huge part of the required know-how is in fact well established. The interest for this metal AM technology has grown substantially in the last 5 years, which is reflected in the increase of published research papers and the high productivity machines developed for the technology [13]. Also, the broad offer of processable materials makes BJ a promising technology for many different industrial and research developments.

The primary challenge when fabricating metal parts with $\mathrm{BJ}$ is to achieve the same densities as those in the conventional powder metallurgy (PM) processes.

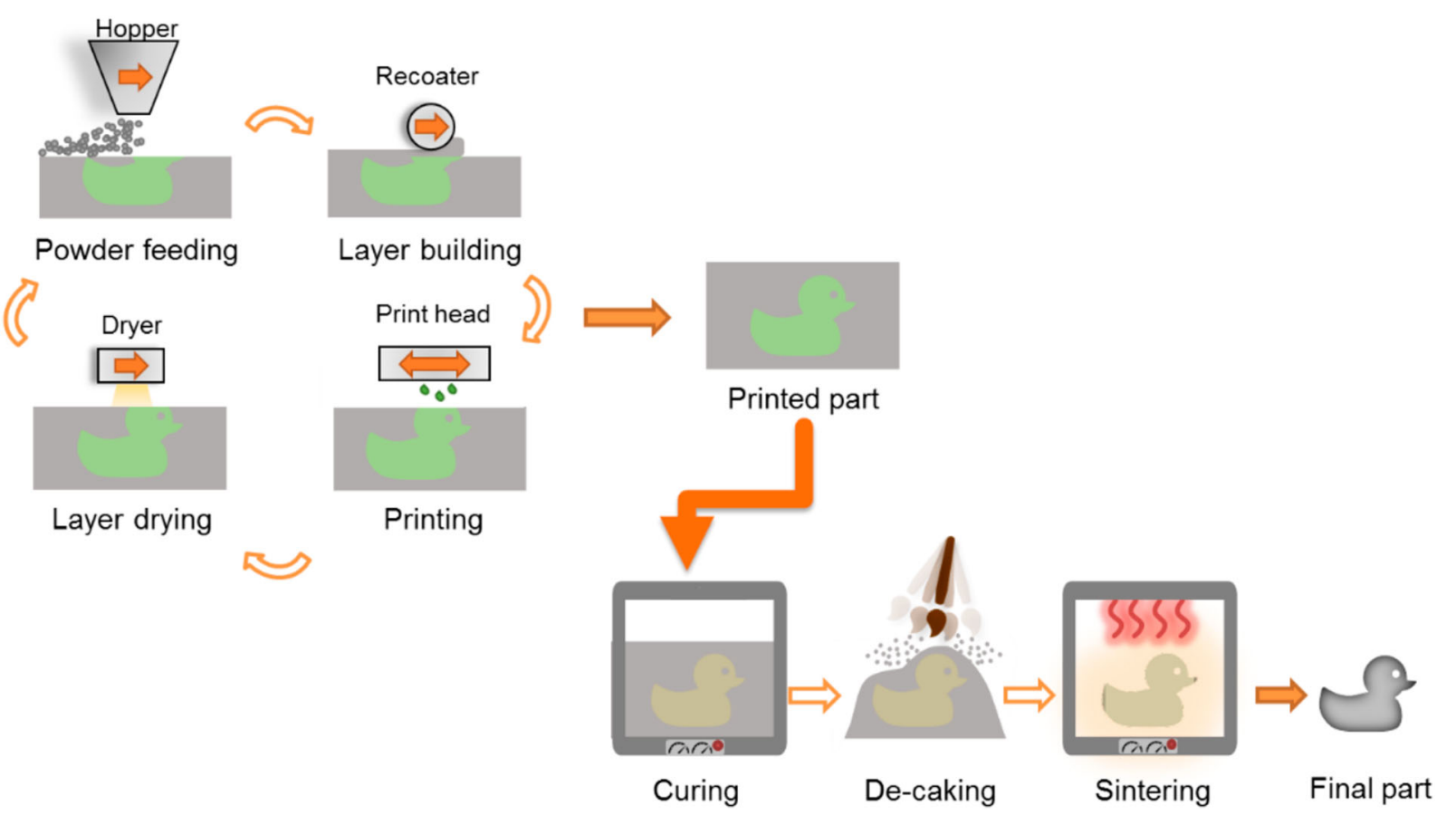

Figure 2. Binder jetting part fabrication process general scheme. 


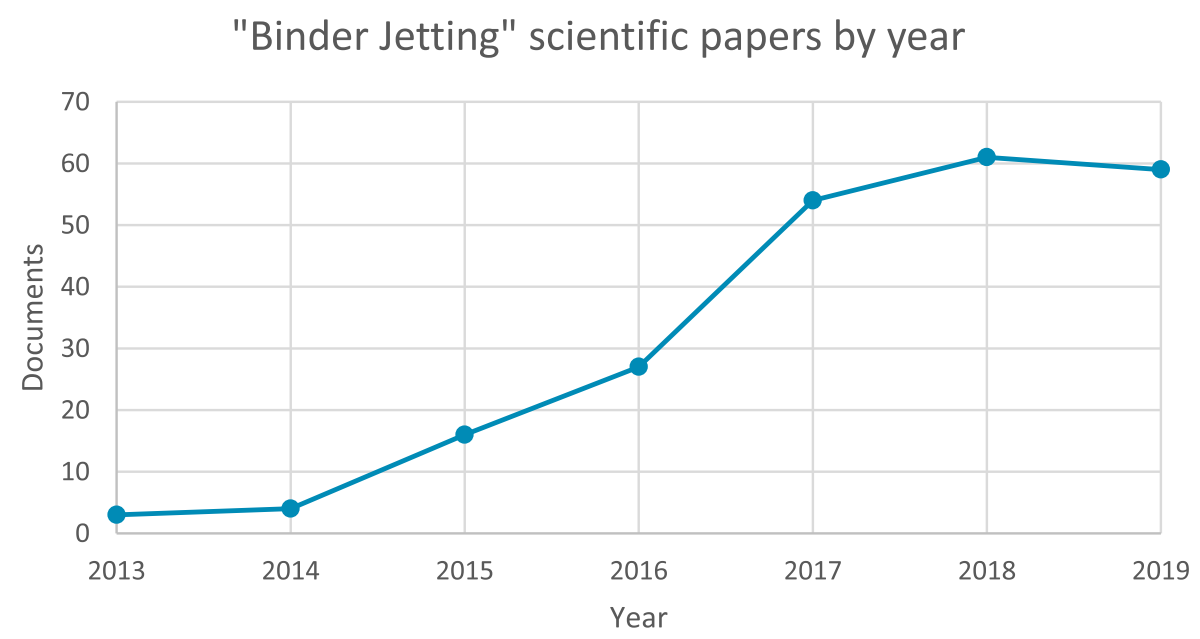

Figure 3. Research documents per year in binder jetting since 2013 according to Scopus ${ }^{\circledast}$ data, at date of September 2019.

Typically, binder jetted parts exhibit a low powder packing densities due to the absence of compacting forces during the printing process [14]. Thus, obtaining highly dense parts is challenging and implies large part shrinkages during the later sintering process. The control of shrinkage is essential to achieve tight dimensional tolerances. Porosity, in contrast, is highly desirable in some applications, for example, in biomedicine, where bone-like mechanical properties, cell migration or good tissue attachment are required [15].

The purpose of this document is to provide an overview of the recent research work in BJ-MAM and to serve as a general guideline for technology users. Considerations regarding raw materials used, process parameter effects and developments in different alloys and MMCs are reported and discussed.

\section{Research work analysis}

Research work made on BJ has increased exponentially during the last decade. Scopus ${ }^{\oplus}$ data for the search term 'Binder Jetting' clearly proves the increase since 2013, which is led by the contributions made in the USA, as shown in Figures 3 and 4. BJ research work covers many different subjects: processability of different metal alloys, technology development and improvement, process parameter optimisation, amongst others.

The metal alloys most studied and reported in literature and their relevance in terms of a number of papers are shown in Figure 5, based on the best knowledge of the authors to date as of September 2019 (based on data obtained from Scopus ${ }^{\circ}$ ). The amount of research published is still small compared with other AM technologies (approximately one hundred papers in $\mathrm{BJ}$ compared with several thousand in PBF-L, for example). Research topics are focused in the preliminary aspects of the technology such as understanding process parameter influence on fabricated part properties, analysis of obtained microstructures, attainable mechanical properties and exploring different ways to obtain full dense metal parts. Due to the inherent porosity issues of the BJ technology, the last issue is in fact the most relevant

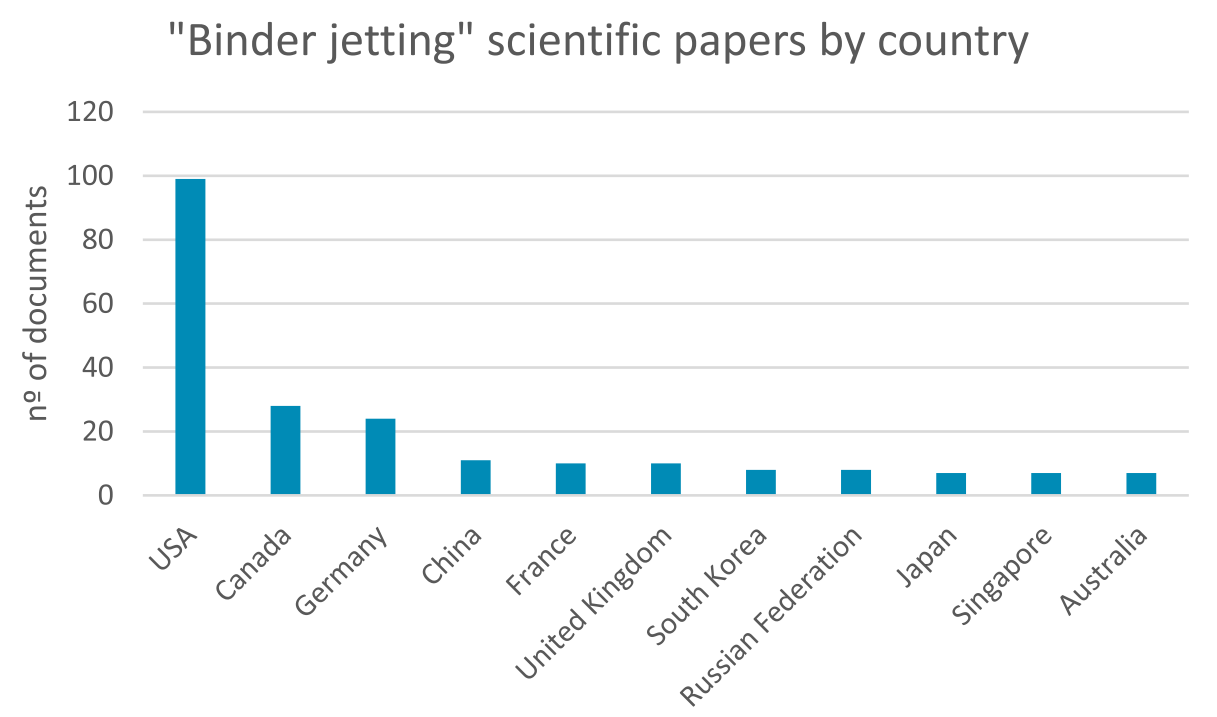

Figure 4. Research documents by country in binder jetting since 2013 according to Scopus ${ }^{\circledR}$ data, at date of September 2019. 


\section{Binder Jetting research developments by metal alloys}

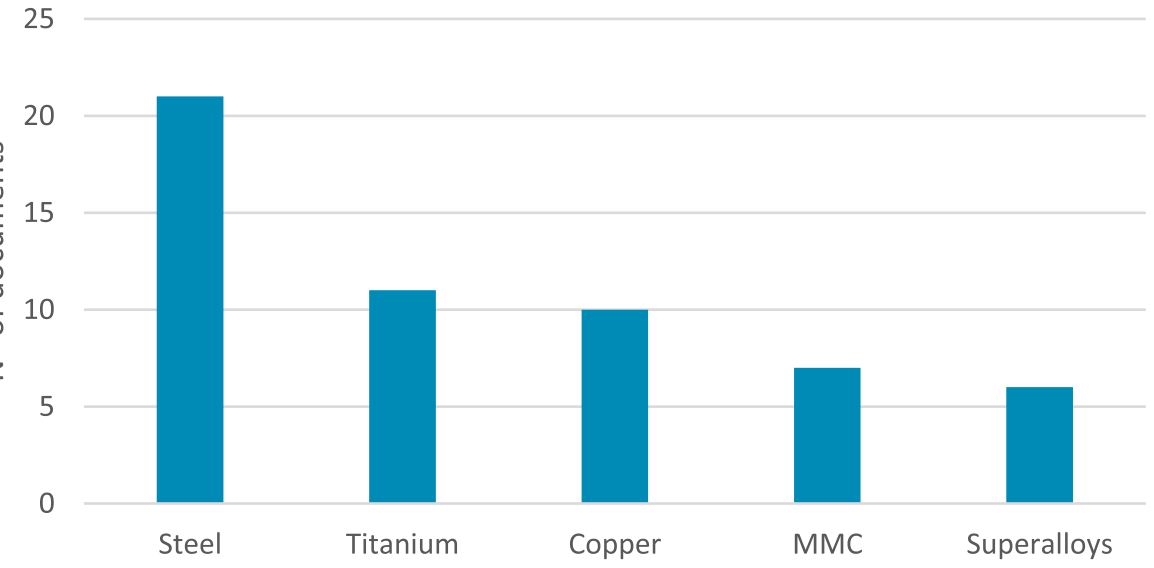

Figure 5. Research document amount about binder jetting metal additive manufacturing reported in the literature.

and studied topic in metal BJ, due to the inherent porosity issues of the technology process.

BJ of steel is especially focused on process development and feedstock material adaptation for density improvement of $316 \mathrm{~L}$ and 420 stainless steels. Regarding nickel-based alloys, preliminary densification studies and microstructure analysis of BJ-processed Inconel 625 and 718 alloys have been performed. BJ of pure copper also has been extensively analysed in order to obtain fully densified parts. Also, advanced nanoparticle suspensions and metal-organic inks have been tested with the aim of replacing organic binders. Additionally, some studies regarding metal matrix composites (MMCs; TiC-Steel, WC-Co, SiSiC and others) have been carried out.

\section{BJ process features and parameters effect}

\section{Considerations about powder feedstock for $B J-A M$}

The availability of commercial metallic powder for metal AM is increasing day by day. Currently, at least 29 common alloys are available, including aluminium, stainless steels, nickel-based alloys, cobalt-chrome and titanium [16]. Powder characteristics, like particle size distribution (PSD), morphology and porosity strongly influence the powder performance properties, like powder packability and flowability, and thus the feasibility to obtain high-quality powder layer and hence final part homogeneity and properties. An incomplete understanding of the effect of the powder characteristics in the whole process may lead to undesired final part properties [16].

Nowadays, there are multiple metal powder manufacturing processes that give powders with different characteristics. Conventional metal powder used in some PM processes, usually water atomised and with irregular shapes, are not suitable for AM purposes due to poor self-compacting capability and low flowability [6]. In contrast, powder used in AM should be the most spherical shaped possible in order to achieve adequate process performance and thus better part properties. Almost all recently published works in BJ-AM area have used Gas Atomized (GA) powders, as they are a reliable and relatively cheap feedstock. Differences between Water Atomized (WA) and GA powders for BJ-AM were studied and reported [17], concluding much better performance and part densities for GA ones. Also, PREP titanium powders have been tested in $\mathrm{BJ}[18,19]$.

\section{Powder selection and characterisation}

Powder selection for BJ-MAM implies the well understanding of the whole manufacturing process. On one hand, the used powder should be easily processable in order to assure higher process stability and robustness, as well as homogeneous powder bed and part properties. On the other hand, the powder should facilitate the sintering process.

The main issue is that powder characteristics that improve its processability penalise its sinterability, and vice versa. Therefore, the correct selection of powder material is not an obvious task. A huge amount of information and powder properties must be considered, and for this reason, the use of correct powder characterisation parameters and techniques is a key point to achieve a reliable, controllable and repeatable AM process.

Current efforts for standardising AM powder characterisation can be seen in the recent ASTM F3049-14 'Standard Guide for Characterizing Properties of Metal Powders Used for Additive Manufacturing'. Nevertheless, there are some standardisation needs for AM that are currently under discussion. These are, for example, [20], the machine-to- 


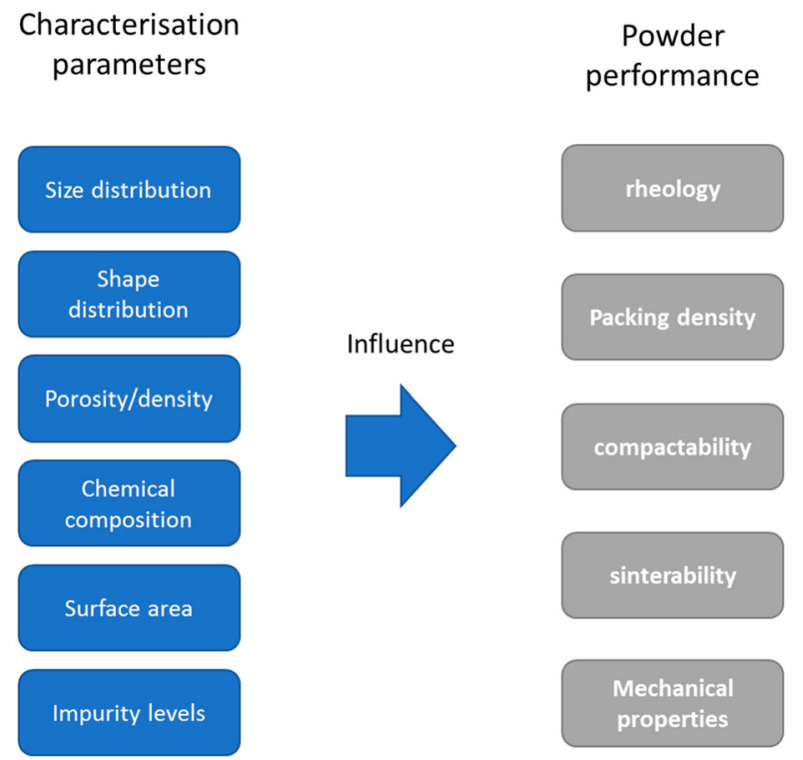

Figure 6. Powder typical characterisation methods and its relationship with powder performance. Adapted from [21].

machine or day-to-day variability, the specific need of powder characterisation methodologies and issues regarding raw material reusability. The relation between characterisation parameters and powder performance is quite complex as there are multiple interactive effects [21], as shown in Figure 6. Therefore, powder parameters substantially influence some key factors that must be well understood and optimised [21]:

- Powder flow behaviour for sufficient and consistent feeding/spreading.

- Powder packing for maximum layer density.

- Particle porosity that affects sinterability and final part density.

- Impurity levels that affect final part mechanical properties.

\section{Powder density, morphology and PSD}

Along with particle morphology, PSD may be the most important factor or parameter to consider for understanding general powder behaviour or processability in BJ-AM. The packing density of the powder bed in $\mathrm{BJ}$ will be absolutely influenced by the correct selection of powder or powder mixtures with appropriate PSD. Powder bed density has been found to be often between powder apparent and tap densities on powder bedbased AM technologies [22-24]. Since the layers are created with little or none compaction force, the apparent and tap density play an important role in the powder bed characteristics. $\mathrm{BJ}$ requires special attention as finer powder is often used comparing with other AM methods. Fine powders are more active in sintering, as there is more surface interaction between particles per volume. Nevertheless, the interparticle friction is also increased, which promotes the particle bridging and agglomeration. These phenomena decrease powder packability [25] and flowability. Therefore, powder tap density, whose determination is gathered in ASTM B527 standard [26] is also used to determine the powder bed packing capabilities, as it will be the maximum attainable packing level of the powder bed. Some researchers report that tap and bulk density measurement methodologies have high dependence on experimental procedures and propose dispersed density called technique as a high reproducibility method which does not induce any powder compaction [27].

Another relevant parameter is the powder or skeletal density, usually measured with inert gas pycnometry [28], that analyses particle inner porosity, possible cracks, satellites and also phase composition of the material or alloy content, as density depends on possible alloying elements of the metallic material. However, the accuracy of the process depends on the used material and operation parameters and can vary between $0.02 \%$ and $0.1 \%$, making it a non-easily repeatable process [29].

The PSD will strongly influence the achievable packing density of a powder. Wider PSD gives higher packing densities compared with narrower PSDs [25]. For large powders, in fact, the packing density is only function of PSD and particle shape and independent of particle sizes [30]. This statement is not valid for fine powders, where the interparticle forces are dominant in powder packing. Bimodal powder mixtures are effective means for increasing packing density. Some theoretical and experimental studies conclude that at higher particle size ratio of the mixture, higher packing density can be obtained. As can be seen in Figure 7, this relation is increased if coarse particle weight per cent is in between $55 \%$ and $75 \%$ [21,30]. However, these studies were carried out assuming perfectly spherical particle shapes and may have some uncertainty compared to real powders. Nevertheless, thanks to the ongoing increase in computational power and software optimisation developments, particle packing simulation software may provide a practical tool for future research or studies for AM [31-35].

As mentioned before, particle morphology will strongly influence the powder packability and flow behaviour. Irregular or non-spherical particles, due to the higher interparticle friction, exhibit lower random packing density [25]. Therefore, the green density of printed parts is also affected and thus sintered part density and shrinkage [36]. There are not specific standards or guidelines for AM particle shape measuring, but there exist some national standards that describe and characterises powder particle shapes. An example of powder shape characterisation according to Russian GOST 25849 is shown in Figure 8(a) [37]. Additionally, $\mathrm{X}$-ray computed tomography and scanning electron 
a)

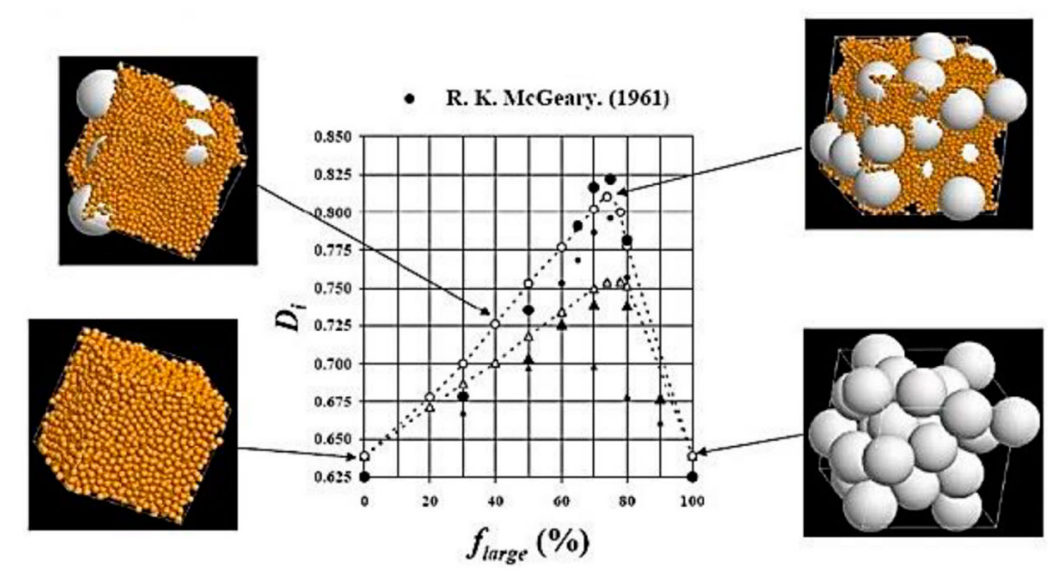

b)

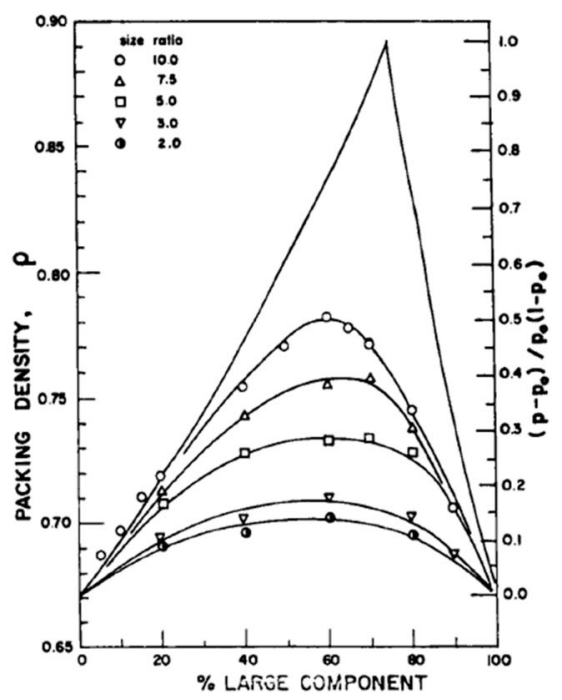

Figure 7. (a) Comparison of McGeary and DEM simulations of theoretical packing densities of bimodal powder mixtures [21] and (b) variation of packing density with size ratio and composition of binary mixtures with log-normal size distributions [30].

microscope (SEM) are commonly used for particle shape determination purposes.

\section{Powder rheology}

Flowability of powders is one of the main concerns in BJ-MAM as it will determine the suitability of the powder processability. The current trend in $\mathrm{BJ}$ is to increase final part densities and to this aim very fine powders, bimodal mixtures or sintering additives are being used. Fine powders, despite their adequacy for sintering purposes, tend to agglomerate affecting their spreadability and flowability and are challenging to process [38].

Traditionally, a Freeman rheometer has been used for determining powder dynamic properties [39]. Despite its robustness, the measurement of powder avalanche angle and surface fractal measurement with powder rotating drum analyser may be a better way to characterise powders for AM [40,41]. Due to the powder flow similarities between rotating drum a)

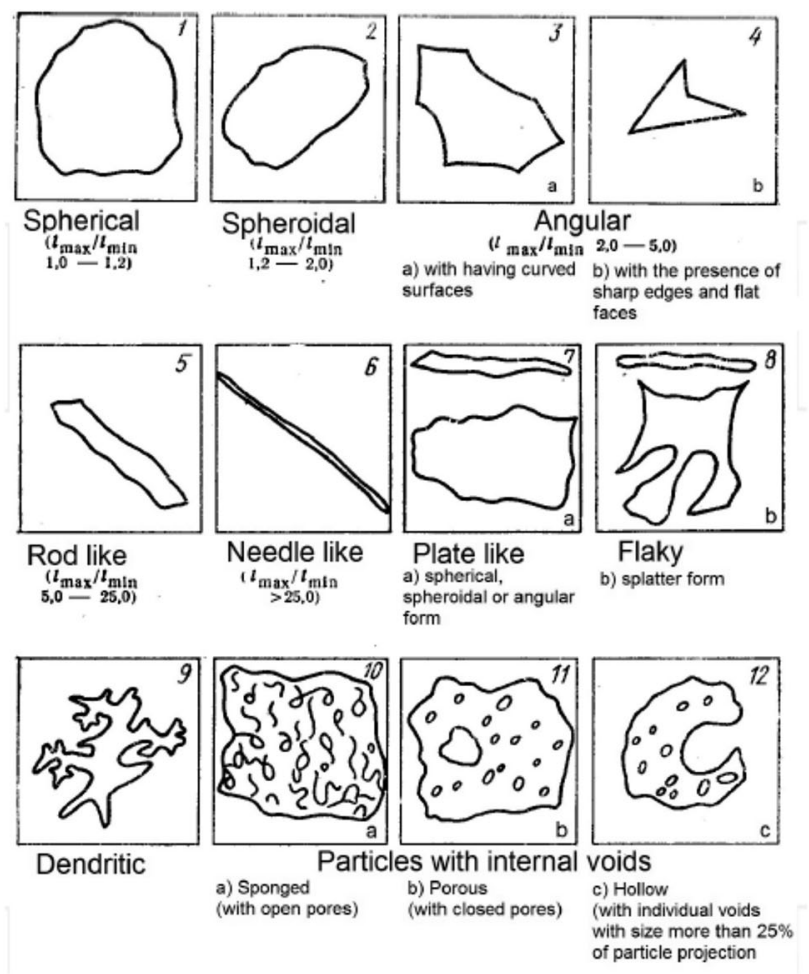

b)

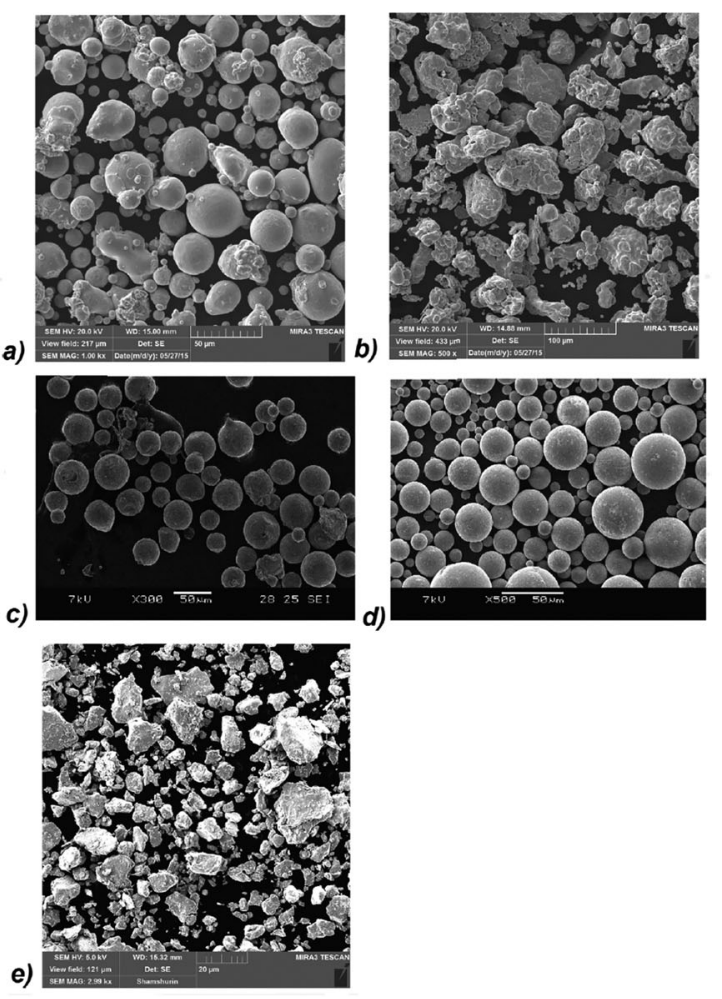

Figure 8. (a) Powder shapes according to GOST 25849 and (b) different powder batches: (a) gas atomised In718; (b) chemical reduction Fe; (c) gas atomised Ti64; (d) plasma atomised Ti64 and (e) mechanically alloyed Fe-Cr-Ni-Mn alloy [37]. 
Table 1. Properties of bimodal powder mixtures compared with initial powders used in copper BJ [45].

\begin{tabular}{lccccc}
\hline $\begin{array}{l}\text { Fine } \\
\text { D50 } \\
(\mu \mathrm{m})\end{array}$ & $\begin{array}{c}\text { Coarse } \\
\text { D50 }(\mu \mathrm{m})\end{array}$ & $\begin{array}{c}\text { Weight } \\
\text { ratio (fine/ } \\
\text { coarse) }\end{array}$ & $\begin{array}{c}\text { Relative loose } \\
\text { powder } \\
\text { density }(\%)\end{array}$ & $\begin{array}{c}\text { Relative tap } \\
\text { powder } \\
\text { density }(\%)\end{array}$ & HR \\
\hline 5.5 & - & - & 41.7 & 55.6 & 1.33 \\
17 & - & - & 52.9 & 65.1 & 1.23 \\
30 & - & - & 48.5 & 60.8 & 1.25 \\
77 & - & - & 56.1 & 64.9 & 1.16 \\
5.5 & 17 & 0.37 & 54.6 & 67.4 & 1.23 \\
5.5 & 17 & 2.7 & 47.3 & 60.5 & 1.28 \\
5.5 & 30 & 0.37 & 53.7 & 63.9 & 1.19 \\
5.5 & 30 & 2.7 & 54.4 & 61.2 & 1.12 \\
17 & 77 & 0.37 & 59.7 & 66.9 & 1.12 \\
\hline
\end{tabular}

rheology analyser and powder bed-based AM technologies, one can have a precise idea of powder flow behaviour under AM process conditions.

Nevertheless, these methodologies are not yet extensively used for BJ-MAM purposes, maybe due to the lack of consistency in flowability standards for AM. Thus, more extensively used qualitative indexes for measuring the flowability and packability of powders are the Hausner ratio and Carr indexes, which give a cheap and fast preliminary idea of powder behaviour. Although both indexes have been criticised for lack of theoretical basis and for being uncomplete methodologies for the correct characterisation of powder flowability for AM purposes [39], they give an empirically tested accurate qualitative value of powder processability [42-44].

Table 1 shows some data from the study of the influence of bimodal size powders in BJ performed by Bai et al. [45], in which the Hausner ratio is calculated for different $\mathrm{Cu}$ powder and their mixtures. As it can be seen, some powder mixtures have improved flowabilities compared to the monomodal powder. This means that higher packed powder bed can be obtained without, in some cases, penalising the powder processability.

\section{Powder feeding and layer building}

Powder feeding refers to the printing stage where powder material is deposited and conditioned to properly form the powder bed layers. In this phase, the powder recoating system builds up a new powder layer on top of the powder bed. In general, there exist two different recoating systems: Parallel deposit/powder bed and Hopper recoater. In order to enhance the sintering activity, finer powders are preferred for BJ-AM. Fine powders processing is usually challenging as fine particles tend to agglomerate [25]. The application of vibration reduces powder bulk strength and the wall friction, substantially increasing the ability of the material to flow [46]. Thus, Hopper recoaters, which usually incorporate vibration systems, are more suitable for fine powder processing.

The powder spreading system is commonly a counter-rotating roller or a doctor blade. Counter-rotating function of the roller is to fluidise the powder material, decreasing the shear forces in the previously processed layers and allowing better packing of powder particles [47,48]. Some new approaches also include ultrasonic vibrating rollers and double smoothing techniques that increase obtained green densities and decrease powder layer defects [49]. With the doctor blade, as the powder is not fluidised with blade-spread systems, usually ultrasonic vibrating blades are used for shear stress-reducing purposes. The reduction of adhesive interaction between the blade and fine cohesive powders has been found to improve layer uniformity [50].

The main parameters that rule the recoating stage are the powder supplying system parameters (depends on the system), layer thickness and roller motion (roller traverse speed and roller rotation speed).

Crack formation during the printing of the first layers has been reported due to layers displacement by the roller shear forces. For this reason, roller translation and rotational speed decreasing is recommended for solving this issue [51]. Although lower spreading speed could significantly increase the printing time, higher powder spreading speed would decrease powder uniformity and packing density [52]. It is important to remark that finer particles will require slower spreading speeds for the correct setting of the powder bed $[53,54]$. At the end, the powder bed density determines the final part density. Poor flowability fine powders, although they are more active during the sintering process, result in low density and non-uniform powder bed and the consequent achievable final sintered densities [55].

Additionally, it has been found that the dimensional accuracy of printed parts varies for parts located in different zones along the printing area [56]. Parts located near to the feeding zone (first area where roller goes through) have better dimensional accuracy than parts located on the opposite side. Note that this phenomenon may not occur in BJ machines with hopper-based recoaters instead of foot or parallel powder bed feeding systems.

Green part strength, although closely correlated to binder saturation level (BSL), is also directly influenced by the powder feeding amount. With higher powder excess level during layer formation, the roller induces higher compacting forces when it spreads the powder [57]. Also, the increase of spread speed or transverse roller speed will decrease the green part strength due to the loose of uniformity and powder packing [52,53]. Sang-Joon John Lee [58] also concluded that thinner layer spacings, thicker powder excess levels and high vibration levels of the counter-rotating roller contributes to raise the packing density of the powder.

There is not a specific rule that correlates the powder particle size and process layer thickness. As it is obvious, the minimum layer thickness should be at least thicker than the diameter of the larger particles presented in the powder feedstock. In Figures 9 and 
Layer thickness and particle size relation

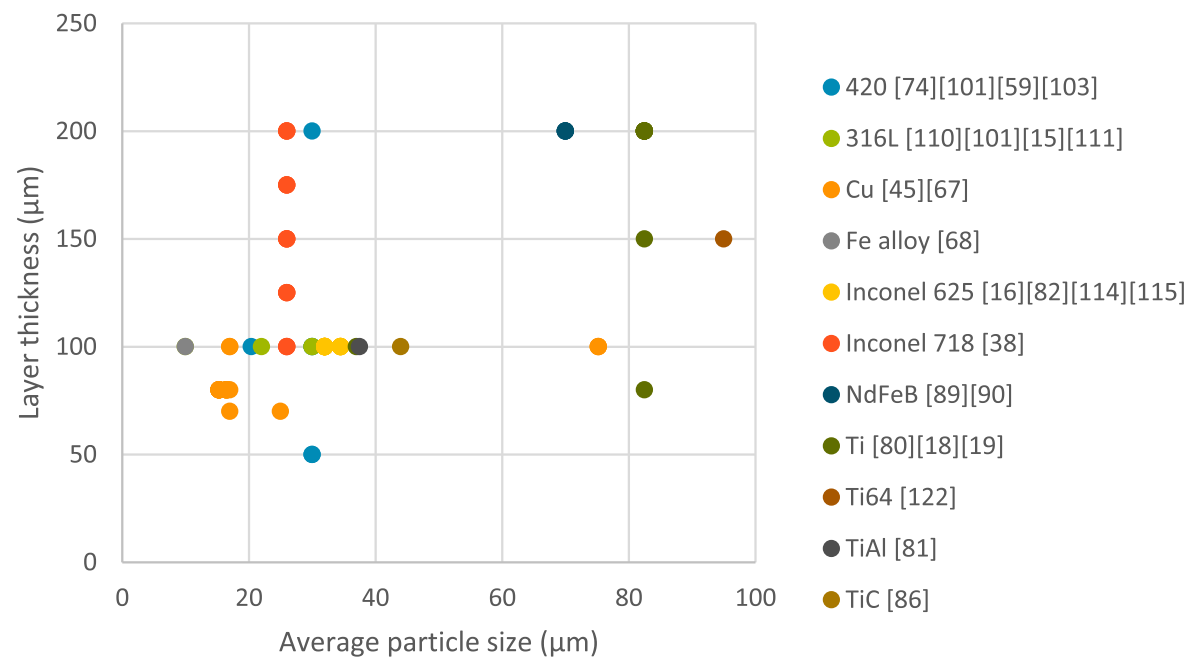

Figure 9. Relation between layer thickness and particle size, obtained from literature data.

10 , a guidance data relating average powder particle sizes and process layer thicknesses used in recent $\mathrm{BJ}-\mathrm{AM}$ developments are presented, as well as this particle and layer size relation with obtained final part density.

As it can be seen in Figure 9, research works reflect the broad range of materials, used powder sizes and usable layer thicknesses in BJ-AM. Thicker powder layers will permit to decrease process time, while thinner powder layers allow processing very fine powders with lower surface roughness and higher part qualities and accuracy [59]. For example, $1 \mu \mathrm{m}$-sized Barium Titanate powders were successfully printed using $30 \mu \mathrm{m}$ layer thickness by Gaytan et al. [60]. Additionally, thinner layer thicknesses increase part surface quality, decreasing surface roughness due to the smoothing of staircase effect phenomena [59,61]. As shown in both Figures 9 and 10, to this day there is not a direct correlation between used layer thickness/ particle size and achieved final part density, as the influence of some other factors like sintering cycle and material chemistry is not considered. However, based on the research work data, most used layer thickness/particle size ratios lie between 3 and 6 , as shown in Figure 10, deducing that this is the appropriate value range for adequate material processing in $\mathrm{BJ}$.

\section{Binder deposition, layer drying and binder curing}

Print-head deposits binder droplets onto the surface of the previously formed powder layer. The leading printing parameter of this stage is the BSL. The BSL defines the deposited binder amount by the print-head, which is related to the packing density of the powder bed. In other words, the BSL (measured in percentage) is defined as the ratio of binder volume to the pore volume in a predefined envelope of powder bed [62].
The BSL directly depends on the print-head dropon demand system capacity, that is, on fixed droplet volume print-heads or adjustable droplet volume print-head. This will determine both the minimum attainable BSL and the droplet overlapping or overlaying mechanisms for reaching higher BSLs [54]. This parameter is of great importance as it will influence the printed part accuracy, surface quality, green part strength and thus part handling capacity. Therefore, the correct set of BSL is critical for the correct process performance.

\section{Binder-powder interaction}

Some BSL theoretical models have been developed and experimentally tested for better comprehension of binder permeation and for determining the equilibrium saturation conditions. Results determine that the equilibrium conditions of the binder permeation are predominantly influenced by the capillary pressure $[62,63]$. Nevertheless, the binder interaction with powder surface is difficult to measure due to the existence of internal microscopic surface along the powder particle which is not wetted by the binder and thus will overestimate the optimal saturation level of the theoretical model. Also, the real drop penetration area does not fit with the drawing area of deposited binder drop [64] thus introducing another possible mismatch in desired BSL and the real one, as well as affecting the printing resolution.

Further binder drop/powder bed interaction studies show the importance of achieving a closely packed powder bed to avoid macro-voids, generated from the heterogeneous packing of loose powder. Those macro-voids do not participate in liquid flow with the consequent inhibition of liquid path [65]. Additional research work that studies the energetic interaction between droplets and powder bed [66], 


\section{Final part density vs layer thickness and particle size ratio}

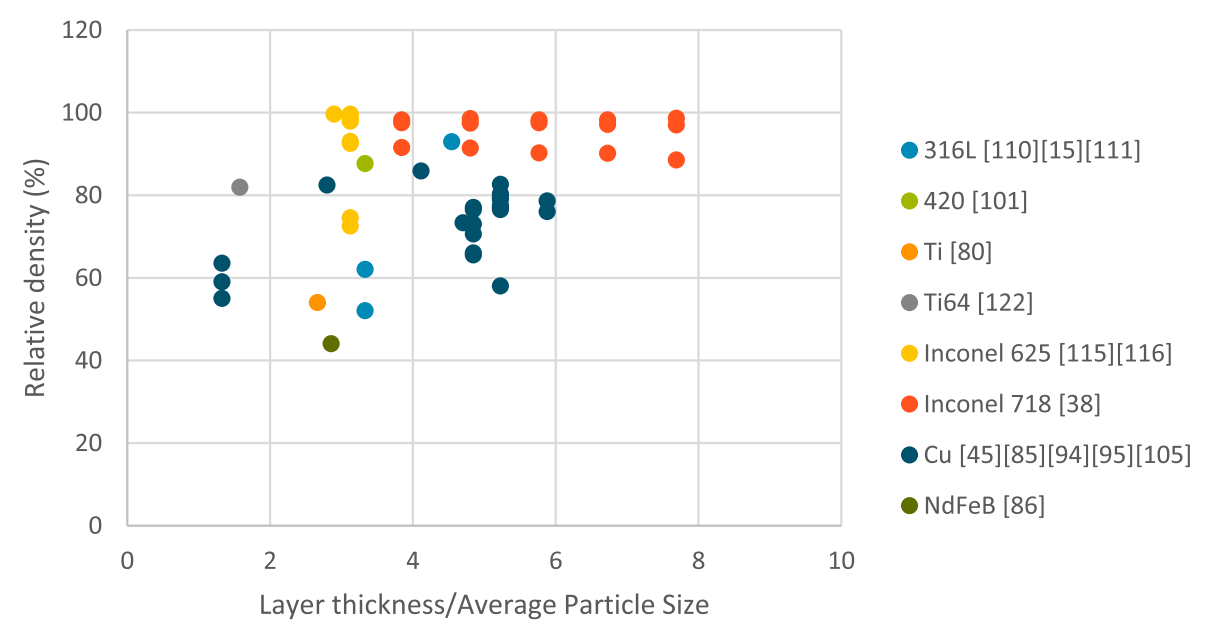

Figure 10. Relationship between final part density and layer thickness/average particle size relation, obtained from literature data.

and drop impact and its influence on liquid penetration driven by $3 \mathrm{D}$ simulations [67], shows the high complexity and the long way to go in terms of analysing and optimising the binder deposition onto powder bed substrates.

A lot of research works reported crater and groove formation on powder bed surface due to binder drop deposition in BJ-AM. These defects lead to a higher interlayer porosity [45], less surface quality and lower green part strength. In fact, the dynamic binder-powder interaction analysed by high-speed synchrotron $\mathrm{X}$ ray imaging, revealed a sub-surface movement and particle ejection due to the binder droplet impact that could potentially increase porosity in printed parts [68]. Also, it was observed that for fine particles, consecutive binder droplets coalesce forming large agglomerates that may interfere with the consecutive powder layers generating defects [68].

Additionally, some research work in powder granulation area may suggest the potential feasibility of using liquid foam droplets instead of liquid droplets due to the improved liquid distribution efficiency and liquid usage in loosely packed powder beds [69].

\section{BSL influence in part quality and dimensions}

Miyanaji et al. [70] reported a linear correlation between printing speed and dimensional accuracy in Y-direction, which is the direction parallel to printhead motion and binder deposition. Also, part dimensional accuracy in X-direction seems to differ from the Y-direction accuracy, mainly due to the asymmetric droplet deposition and different shear forces involved in consequent powder layer spreading. Additionally, as higher printing speed results in printed part volume increase, the equilibrium BSL decreases for the same binder amount used deteriorating the printed part mechanical strength. Also, higher expansion rates in
$Z$ direction than in $X$ and $Y$ building directions were reported due to binder bleeding and sticking [71].

Furthermore, BSL was determined to have a direct relation with part surface quality as reported by Chen and Zhao [59]. Lower saturation levels lead to a lack of bonding between powder particles and thus particles detach from the printed part. On the other hand, too high saturation levels permit an excess of powder bonding to the surface, leading to a poorer surface quality. Therefore, an equilibrium BSL must be set in order to obtain optimum surface quality. Nevertheless, higher BSL increases green part strength and thus part integrity while it is handled $[53,56]$. Thus, optimum BSL for surface quality improvement may not assure a minimum or optimum green part strength.

Inkjet problems in $\mathrm{BJ}$ may manifest depending on the part orientation during manufacturing producing visual differences on the product surfaces, caused by powder particle disposition among the surface and the projection of ink droplets on the oriented surfaces of products. Gardan [72] performed a printing characterisation and texture quality improvement, fabricating test specimens for visual observation, image processing and texture quality analysing with pixel scanning aided by a computer software. The author demonstrates that samples printed in XY plane had better quality regarding texture contrast and quality. Also, image contour correction algorithms were developed for better quality and image contour accuracy for inclined plane profiles. The research thus proposes an approach able to improve the texture quality in $\mathrm{BJ}$ in all manufacturing directions.

\section{Binder systems}

Many different binder types are now being tested and used in BJ. Ethylene glycol (EG) based binders are maybe the most extendedly used ones. Their excellent water solubility, inexpensiveness, long-lasting and 
Table 2. Commonly used binder systems and curing cycles in binder jetting.

\begin{tabular}{|c|c|c|c|c|}
\hline Binder & Material & Curing temperature $\left({ }^{\circ} \mathrm{C}\right)$ & Curing time & Reference \\
\hline EGBE/IPA/EG & 316 & 195 & $2 \mathrm{~h}$ & {$[74]$} \\
\hline EGBE/IPA/EG & 420 & 195 & $2 \mathrm{~h}$ & [74] \\
\hline $\mathrm{EG} / \mathrm{DEG}$ & $316 \mathrm{~L}+316 \mathrm{~L}$ nano & 200 & $2 \mathrm{~h}$ & [75] \\
\hline ExOne LB 04 & $420+$ Cu nano & 200 & $2 \mathrm{~h}$ & {$[76]$} \\
\hline N.A. & 316 & 175 & $3 \mathrm{~h}$ & {$[15]$} \\
\hline PM-B-SR1-01 ExOne & $420+$ Si3N4 & 170 & $2 \mathrm{~h}$ & {$[77]$} \\
\hline DEG & Glass iron & 200 & $2 \mathrm{~h}$ & [78] \\
\hline PVA/IPA & Metal oxides & Infrared lamp & $20 \mathrm{~min}$ & [79] \\
\hline PVA/PVP & $\mathrm{Ti}$ & Air dried & $24 \mathrm{~h}$ & [80] \\
\hline ZB60/3D Systems & $\mathrm{Ti}$ & Air dried & $1 \mathrm{~h}$ & [51] \\
\hline PM-B-SR1-04 ExOne & $\mathrm{Ti}+\mathrm{Al}$ & 200 & $2 \mathrm{~h}$ & [81] \\
\hline EGME/EG ExOne & $\ln 625$ & 175 & N.A. & {$[82,36]$} \\
\hline EGME/EG ExOne & $\ln 625$ & 175 & N.A. & [83] \\
\hline N.A. & $\ln 718$ & 80 & $2 \mathrm{~h}$ & [38] \\
\hline DEG ExOne & In 718 & N.A & N.A. & [84] \\
\hline PM-B-SR1-04 ExOne & $\mathrm{Cu}$ & 190 & $2 \mathrm{~h}$ & {$[85]$} \\
\hline $\begin{array}{l}\text { PM-B-SR2-05 } \\
\text { ExOne }\end{array}$ & $\mathrm{Cu}$ & 190 & $2 \mathrm{~h}$ & {$[45]$} \\
\hline ProMetal R-1 ExOne & $\mathrm{TiC}+\mathrm{Ti}$ & 200 & N.A. & {$[86]$} \\
\hline Dextrine/Glycerine & $\mathrm{Si} / \mathrm{SiC}$ & Air dried & $24 \mathrm{~h}$ & [87] \\
\hline Dextrine/Glycerine & $\mathrm{Ti}_{3} \mathrm{SiC}_{2}$ & Air/70 & $24 \mathrm{~h} / 24 \mathrm{~h}$ & {$[88]$} \\
\hline DEG aqueous & $\mathrm{NdFeB}$ & $100-150$ & $4-6 \mathrm{~h}$ & {$[89,90]$} \\
\hline Polysaccharide based starch & $\mathrm{Si}$ & N.A. & N.A. & [91] \\
\hline
\end{tabular}

Table 3. Summary of the main advantages and disadvantages of different binder systems for BJ-AM [95].

\begin{tabular}{|c|c|c|}
\hline Binder/Ink type & Advantages & Disadvantages \\
\hline Polymeric & $\begin{array}{l}\text { - Compatibility } \\
\text { - High green strength }\end{array}$ & $\begin{array}{l}\text { - Pyrolysis and residuals } \\
\text { - Curing process usually required }\end{array}$ \\
\hline Metal particle suspension & $\begin{array}{l}\text { - } \quad \text { No residuals } \\
\text { - } \quad \text { No curing process required }\end{array}$ & $\begin{array}{l}\text { - Particle sedimentation and nozzle clogging problems } \\
\text { - Particle dispersion difficulties } \\
\text { - Oxidation of nanoparticles }\end{array}$ \\
\hline Metal salt & $\begin{array}{l}\text { - Clogging risk reduction } \\
\text { - } \quad \text { Ink shelf life increasing }\end{array}$ & $\begin{array}{l}\text { - Metal content limited to salt solubility } \\
\text { - High temperatures and reducing atmospheres for metal salt } \\
\text { reduction }\end{array}$ \\
\hline $\begin{array}{l}\text { Metal organic } \\
\text { decomposition }\end{array}$ & $\begin{array}{l}\text { - Lower metallisation temperature than metal } \\
\text { - Calts } \\
\text { - Improved solubility }\end{array}$ & $\begin{array}{l}\text { - Limited metal content } \\
\text { - Low green part strength }\end{array}$ \\
\hline
\end{tabular}

burnout properties make it appropriated for BJ-MAM [73]. Sometimes, BJ machine builders offer its proprietary formulation binders for MAM (as can be seen in Table 2), although the main binding component is usually diethylene glycol (DEG), EG or ethylene glycol butyl ether.

The use of the appropriate binder is essential to ensure good part green strength. This will allow the manipulation of green parts after the curing stage without damaging them. That is not completely true since the selection of powder particle size is sometimes much more determinant than binder composition. Towards improving green part integrity, a research work developed by Kathy Lu et al. [92,93] determine that smaller powder particle sizes improve green part strength, due to the reduced binder spreading rate variations, and the faster and the better binder spreading due to the higher capillarity forces. Nevertheless, the selection of binder system for BJ is critical as it determines the success of creating satisfactory green parts and affects the final properties of the sintered parts [94].
Despite the reliability of polymer-based binders for BJ-AM purposes, they inherently imply certain complexities to the manufacturing process, as listed below by Bai et al. [94,95]:

- Debinding of polymer binders typically require refined sintering profile to facilitate polymer pyrolysis and degassing.

- The pyrolysis of polymer binder could leave residual carbon, which could affect the purity (and thus mechanical, optical and electrical/thermal properties) of the final part.

Although binder residuals are in general not desired due to the degradation that may cause on final part properties, for some purposes, binder residuals are of great importance. For example, during the fabrication of BJ-AM high-performance composites of $\mathrm{Ti}_{3} \mathrm{SiC}_{2}$, dextrin-based binder residual carbon was used to form reactions with both $\mathrm{Ti}$ and $\mathrm{Si}$ [88]. Also, silicone-based resin green part infiltration, along with dextrin binder, allowed to successfully fabricate $\mathrm{SiSiC}$ 
composites thanks to inter-reactions of carbon residuals, $\mathrm{Si}-\mathrm{O}-\mathrm{C}$ residuals and $\mathrm{Si}$ and $\alpha-\mathrm{SiC}$ powder.

Some recent works have also explored the use of different kind of solutions away from polymeric binders, like the use of metal nanoparticle suspensions $[75,94,96,97]$, metal oxide precursors [79,98], metal salts and more recently metal organic decomposition (MOD) inks [95]. The overall advantages and disadvantages of each binder are summarised in Table 3.

These different binder approaches require further studies to a better understanding of their performance. For example, recent efforts made by Bai et al. [99] studied the interaction effect between powder bed and nanoparticle suspension binder, in order to understand the effect of nanoparticle load on BJ process feature resolution and its wettability and spreadability on powder beds built with different powder particle sizes and distributions.

\section{Binder drying and curing}

After the binder deposition stage, a heater lamp passing over the powder bed dries previously printed part layer. Lamp parameter control, like power and drying time will directly impact on the printing process performance. Too high drying temperatures or drying times could promote the part slice cracking during the next powder layer spreading due to the shear forces created by the roller and the fragility of excessively dried layer. On the other hand, too low temperatures or drying times may cause part layer peeling off from powder bed and sticking to the roller. Also, for part shrinkage rate in both $\mathrm{Z}$ and $\mathrm{Y}$ axes, drying time has been found to be the most influential factor according to Chen and Zhao [59]. Too long-time drying times lead to higher green part shrinkage due to binder solidification while very short drying times leaves higher porosity and higher shrinkage after the sintering process. Therefore, drying time plays a critical role both in process correct performance and final part properties.

Miyanaji et al. [52,53] realised that higher heating power cure the deposited binder before it completely joins the particles in the specified area, on the other hand, low heating power leads to insufficiently cured binder, which consequently results in part accuracy deterioration. Moreover, and in line with the results obtained by Chen and Zhao [59,61], the BSL does not seem to have a significant effect on the accuracy or shrinkage of the parts. Also, higher drying times would over-cure the binder which results in week bonds between the successive layers, and consequently decreasing the dimensional accuracy of the parts. Furthermore, the interaction effect of the power level and drying time should always be considered when setting process parameters down, as well as the interaction between binder saturation and spread speed $[53,54]$.
Drying is not usually enough to properly evaporate binder carrier solvent or water, neither for curing binder polymer itself. This also depends in used binder type. In some cases, organic solvent-based thermoplastic polymer binders are used, where no post-curing processes are required $[79,80]$. In other newer approaches, the layer drying lamp is upgraded to reach higher temperatures and sintering nanoparticle-based metallic suspensions instead organic binders [94], as mentioned before. Nevertheless, usually water-based or organic solvent-based thermoset binders are used to print metallic parts. Thus, once all forming slices of the part are printed, the resultant powder volume set is removed from the BJ machine and inserted in a low-temperature binder curing oven. The curing time and temperature will directly depend on the used binder system, printed part geometry, part wall thicknesses and the volume of the powder bed or height of the printed job-box.

\section{Part consolidation stage in BJ}

Binder jetted part consolidation is carried out by a sintering stage, in which powder particles are bonded into a coherent, predominantly solid structure via mass transport events that often occur on the atomic scale, leading to improved strength and a lower system energy [100]. Along with sintering, a previous binder burnout stage is performed, mainly in the same thermal cycle. An absence or a badly traced binder burnout cycle will probably leave residues within the part that can diffuse or react with the metal powder, promoting the creation of non-desirable phases and thus radically changing expected part mechanical, thermal or optical properties.

All powder structures prior to sintering are inherently porous. In the case of BJ, where powder particles are packed almost without the use of external forces, the solid volume fraction of the packed and printed powder parts is usually below 0.6 . Low green part densities will lead to high shrinkages for a certain level of part densification, thus this issue must be considered for BJ-MAM process and part design.

Common sintering mechanisms for BJ-MAM, which depend on used alloy system and thermal cycle characteristics, range from solid-state sintering to infiltration sintering. Attaining full density is difficult and, in many times, is not necessarily a guarantee of satisfactory properties. Moreover, green part fabrication process through BJ gives poorly consolidated and low packing density parts, thus enhanced sintering techniques, specially alloyed materials, sintering aids or consolidation post-processes will be necessary if highdensity parts are required.

For example, Boron-based additives (pure B, BC and $\mathrm{BN}$ ) or silicon nitride can be used for improving 
$316 \mathrm{~L}$ or 420 stainless steels sintered density $[74,101,102]$, as well as bronze as an infiltrant to create pore-free metal composite $[78,103]$. Due to their high alloying element content, superalloys are susceptible to sinter under supersolidus liquid phase sintering (SLPS) mechanism, and thus near-full densities can be obtained in BJ parts with the correct selection of sintering cycle $[38,82,84]$. Hot Isostatic Pressing (HIP) also is an interesting technique for reaching high densities in BJ-AM [104-106], although it involves an additional thermal cycle which increases process cost. For some other developments involving cemented carbides or ceramic preforms, liquid phase sintering [107] through a sinter-HIP or infiltration sintering [86,87] are well-suited mechanisms for obtaining near-full dense parts.

Additionally, the use of bimodal powders permits creating higher packed BJ printed parts and thus improving both sintered density and thermal cycle efficiency. Since the more contact area among particles creates more diffusion paths than in monosized particle systems, the total energy amount required for reaching the same density decreases [55].

Nevertheless, not all the developments in BJ require high part densities. Low sintering temperatures permit creating interconnected porous network [80], which along with a lattice part design, makes BJ-AM an interesting process for implantology or other medical applications $[15,18,19,80]$.

Despite the sintered density of a final part depends on many different and independent factors, like sintering cycle, green part particle packing ratio, material composition ... etc., particle size is directly linked to part sinterability and thus achievable final densities [100].

Figure 11 shows reached the final part relative density versus used powder average size in some BJ-MAM studies. Highest relative densities are achieved in parts fabricated under an infiltration sintering process, as the infiltrant flows within the open pore network leaving almost zero porosity. The optimum particle size for infiltration purposes may depend on the desired final composition and required capillary flow properties for the infiltrant material. SLPS-sintered samples present near-full densities by using relatively small particle sizes between 7 [84] and $35 \mu \mathrm{m}$ [17]. The final density variation for a specific material at a particular particle size is related to the differences on BJ process parameters and sintering cycles. Thus, both Figures 11 and 12 just present a preliminary guidance of the relation range between some process parameters and part properties.

Regarding sintering temperature ranges used for binder jetted parts, and according to [108], almost all the studies remain between 0.8 and $1 T_{s} / T_{m}$, where $T_{s}$ refers to sintering hold up the temperature and $T_{m}$ refers to each alloy melting point or solidus temperature, shown in Figure 12. Data points in which $T_{s} / T_{m}$ relation exceeds the unit value are associated to infiltration sintered case studies. It is worth mentioning that final density disparity for same material relies in used powder particle size and printing parameter differences.

Despite the high printing resolution and complex part building capacity of BJ technologies, one of the main concerns is the relatively high shrinkage that presents near-fully densified parts, as shown in Figure 13. This could lead to part warping and collapse during sintering process. Also, attaining high final part dimensional accuracies could be a handicap due to the inconsistency of powder bed density along the printing volume. Zhao and Wang [71] reported that sintering temperature, rather than sintering time or heating rate, has the major influence on shrinkage for sintered BJ printed parts. Figure 13 provides a perspective view of shrinkage ranges related to final part densities that

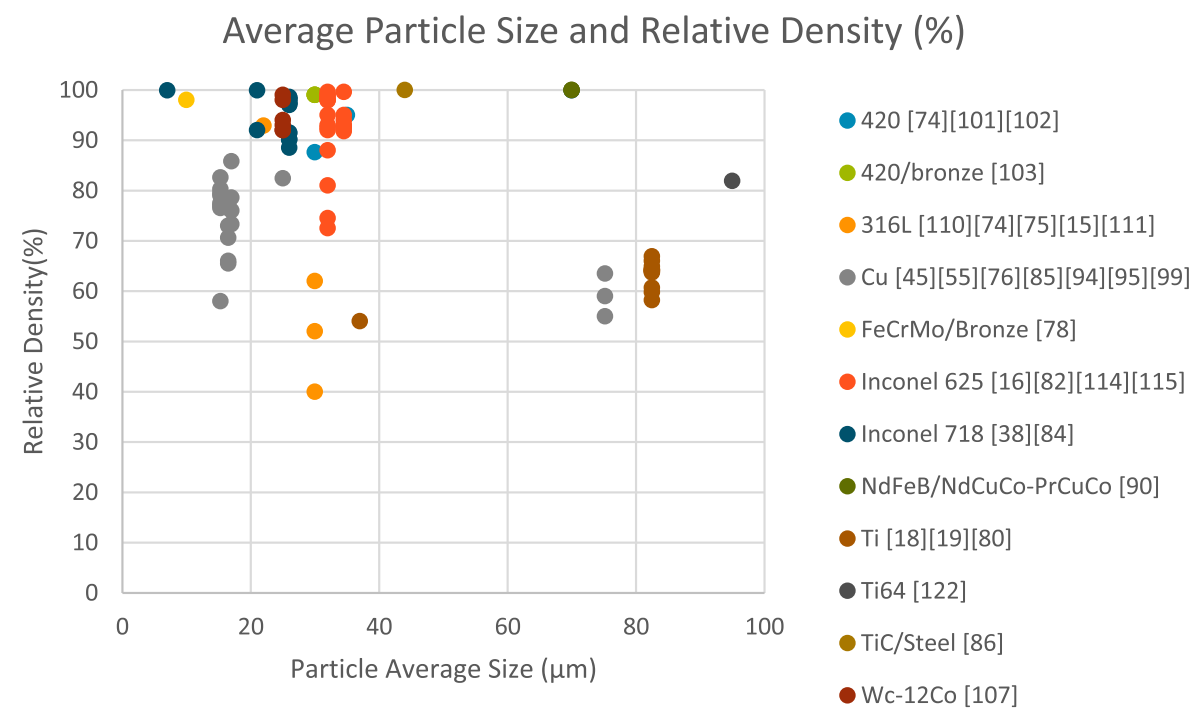

Figure 11. Relationship between final part relative density and powder average particle size, obtained from literature data. 
Sintering temperature and final part relative density

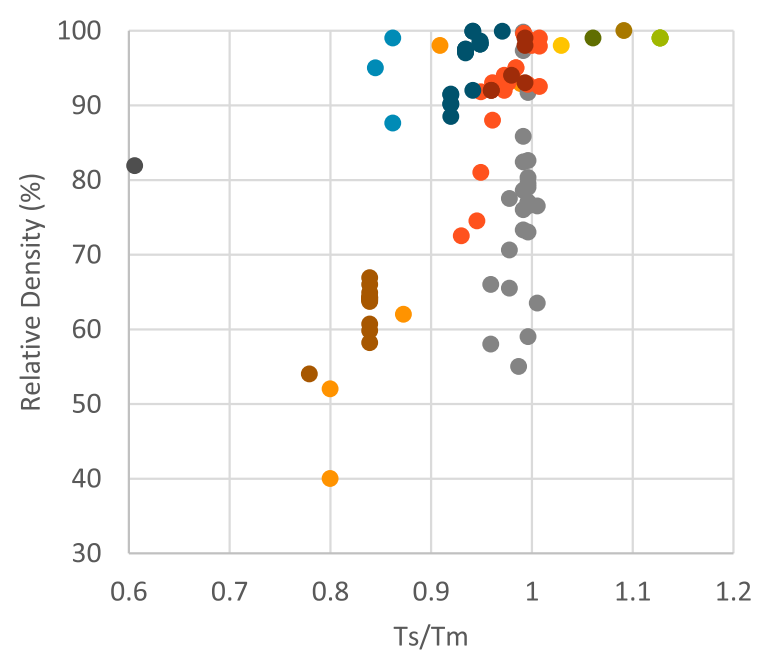

- 420 [74][101][102]

-420/Bronze [103]

- 316L [110][74][75][15][111]

- Cu [45][55][76][85][94][95][99]

- FeCrMo/Bronze [78]

- Inconel 625 [16][82][114][115]

- Inconel 718 [38][84]

- SiSiC [87]

- Ti [18][19][80]

- Ti64 [122]

- TiC/Steel [86]

- WC-12Co [107]

Figure 12. Final part relative density and sintered temperature for different materials processed with binder jetting, obtained from literature data.

one can face when sintering BJ-AM parts. Data from recent research works show that near-full dense part linear shrinkages in $Z$ direction vary between $15 \%$ and $25 \%$, depending on the used material characteristics and sintering cycle.

\section{Materials and properties}

\section{Iron-based alloys}

The low packing density of powder bed is an inner characteristic of BJ process, which implies low final density in sintered parts in many cases. Although for some applications this could be a limitation, porosity is a desired characteristic in tissue engineering. For this reason, and also for the capability of using a wide variety of different materials, BJ is now widely being explored as a feasible solution for bone tissue applications [15] and controlled porosity components development.

As mentioned before, one of the main concerns is the porosity control and customisation of sintered parts. To this aim, Verlee et al. [109] analysed the effect of powder particle sizes and sintering temperatures on final part density, porosity characteristics and permeability. Six different powder batches were tested, with particle sizes ranging from spherical D85 $<22$ to $45-90 \mu \mathrm{m}$ non-spherical powders. Printed parts were sintered during $90 \mathrm{~min}$ under temperatures ranging from 1200 to $1430^{\circ} \mathrm{C}$. Along with sintering conditions, used particle size and morphology determined obtained pore size and size range, and thus part permeability. The increase of particle size decreases the densification factor, leaving more open porosity and larger pore sizes. Moreover, non-spherical powder particles led to lower powder bed packing and

\section{Shrinkage vs Relative Density}

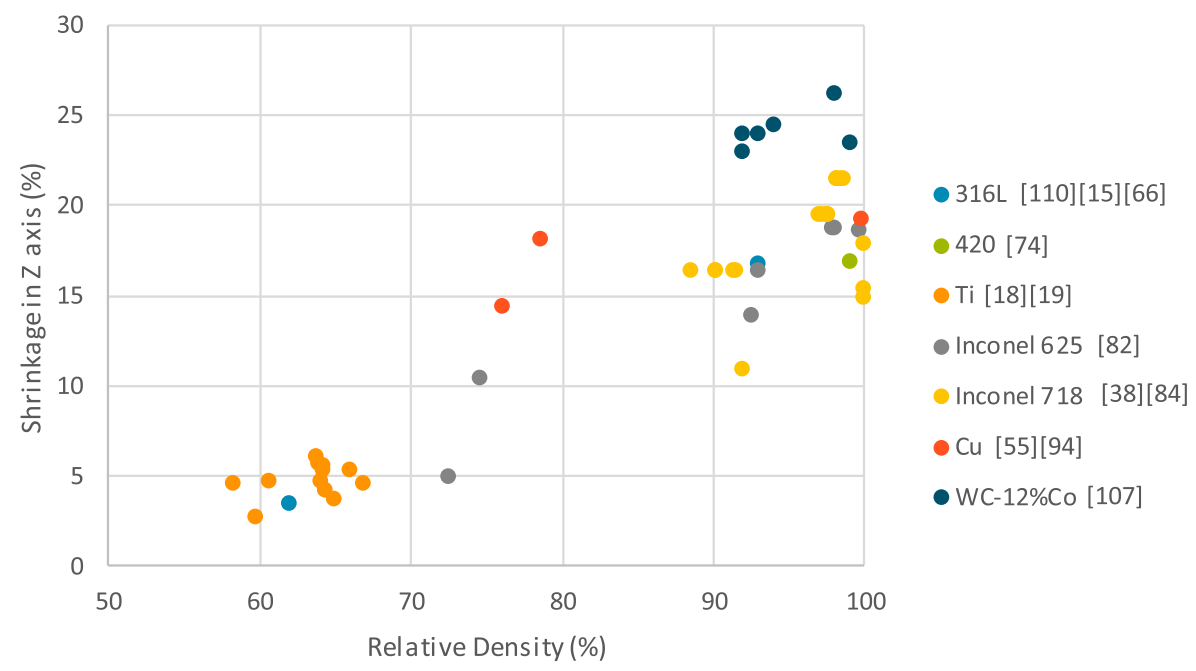

Figure 13. Final part relative density and part shrinkage for different materials fabricated with binder jetting. 


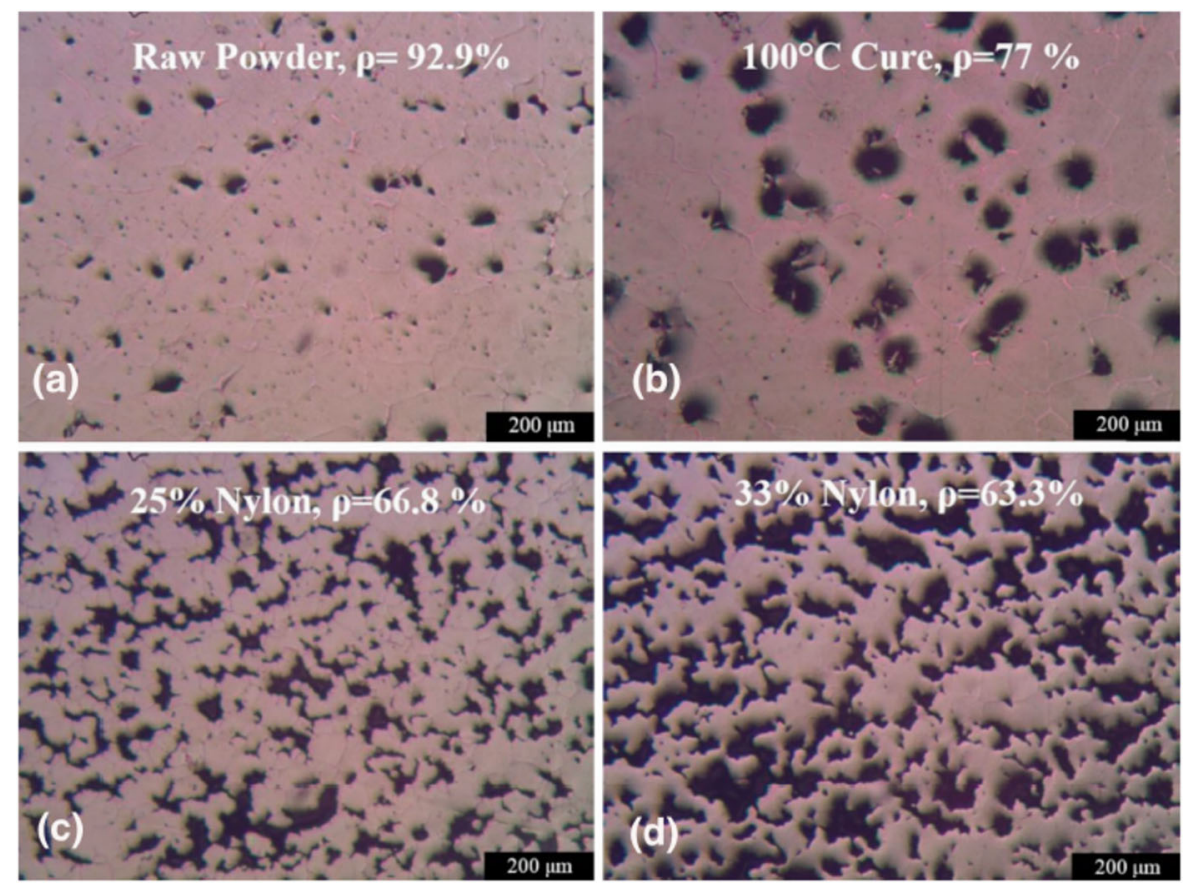

Figure 14. Porosity of the sintered parts made of (a) raw 316 feedstock, (b) powder agglomerates and (c) and (d) $316 \mathrm{~L}+\mathrm{PA}$ mixtures, showing an interconnected porosity [110].

thus to more porosity after sintering. Also, the rough porosity paths left by sintered non-spherical particles, promotes higher fluid pressure loss and thus decreases the permeability comparing with sintered spherical powders of similar sizes.

In a further study, Ziaee et al. [110] carried out an experimental procedure with 316L stainless steel fine powder to create parts with varied final density and controlled shrinkage levels. Two different powder batches were prepared starting from the $<22 \mu \mathrm{m} 316 \mathrm{~L}$ raw powder: agglomerate powder with agglomerate particle size between 25 and $45 \mu \mathrm{m}$, and mixtures of stainless-steel powder and polyamide (PA) powders with an average particle size of $55 \mu \mathrm{m}$, mixed in different volume ratios. Samples were sintered for $60 \mathrm{~min}$ in an $\mathrm{Ar} / \mathrm{H}_{2}$ atmosphere furnace at $1360^{\circ} \mathrm{C}$. The mixtures containing PA were previously processed at $800^{\circ} \mathrm{C}$ to burn out PA from the part, to create interconnected porosity after sintering process, as shown in Figure 14.

Results showed a close relationship between powder bed density and sintered density. Both raw powder and agglomerated powder samples with similar spreading densities (near 56\% relative density) showed similar sintered densities (near 93\%), while $42 \%$ relative powder bed density samples showed final sintered densities of $77 \%$. Authors explained that this may be because the shredding of the agglomerates caused by the roller, increasing powder flowability and packability. Nevertheless, a postprinting sieve analysis detects that only less than $10 \%$ powder was under $25 \mu \mathrm{m}$, and thus agglomerate breaking phenomena did not occur.
Dimensional shrinkage in three directions was also analysed. It is remarkable that in all the parts the shrinkage in $Z$ direction was much higher than in both $X$ and $Y$. This suggests that there may be more porosity in between layers and/or that there exists a higher shrinkage due to gravity forces during sintering. Similar shrinkages are obtained in PA/Steel mixtures, despite obtained less sintered density of $63-66 \%$. Also, the obtained shrinkages between different PA/ Steel mixtures are independent of PA content. These results suggest the development of a process where parts with internal varying porosity can be fabricated without penalising process dimensional accuracy, with customised heat transfer or fluid permeability properties along the same part.

In another study, many cylindrical scaffolds with different lattice shapes and sizes were built by Vangapaly et al. [15], testing final part densities, shrinkages and compressive strength to compare with natural human bone mechanical properties. In this preliminary study, printing parameters were fixed and only sintering parameters were set as varying parameters to compare the obtained results. Results concluded that the fabrication of customised properties scaffolds is possible varying the lattice structure and sintering parameters. In this case, scaffolds with 2-mm circular lattice structure and sintered in $\mathrm{Ar}$ atmosphere at different temperatures and times reached human cortical bone properties, that is, $100-140 \mathrm{MPa}$ compressive strength, modulus of elasticity between 0.8 and $1.8 \mathrm{GPa}$ and densities (relative to the entire scaffold) between 1.8 and $2 \mathrm{~g} / \mathrm{cc}$. Also, sintering temperature has more influence in shrinkage than sintering time. 


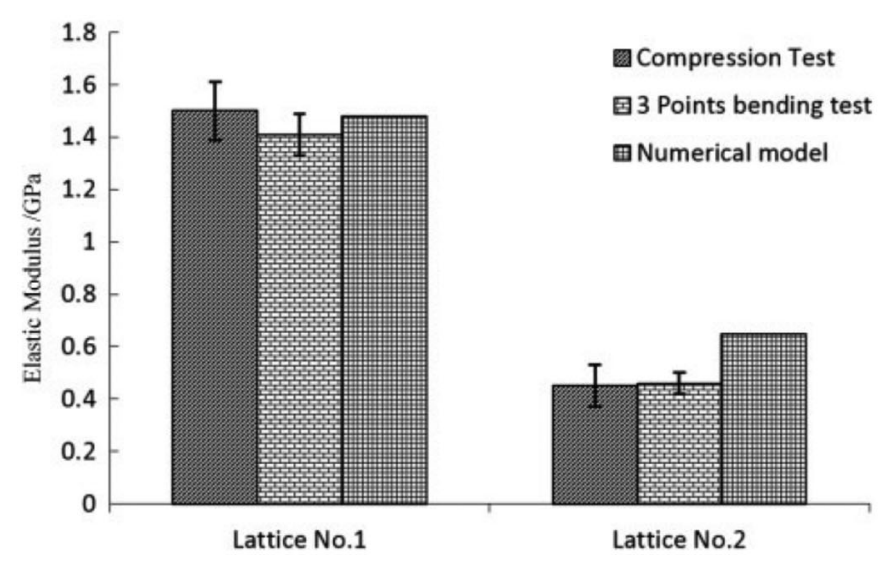

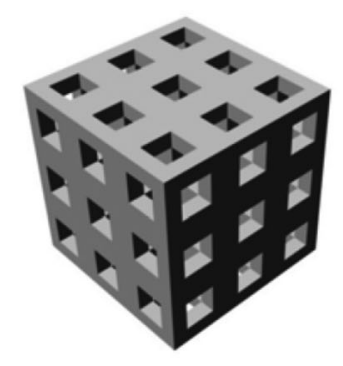

(a) Lattice No.1

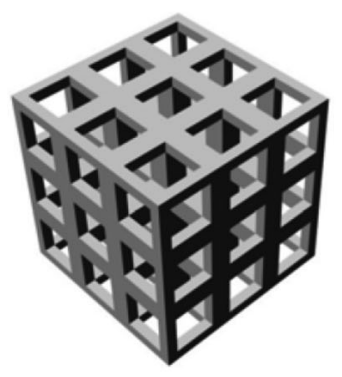

(b) Lattice No.2

Figure 15. Mechanical properties of fabricated Lattice structures [111] compared with numerical model forecasting.

Nevertheless, the authors explain that further investigations should be performed to ensure the feasibility of BJ for this kind of applications, testing fabricated parts biocompatibility and wear resistance.

In line with the previous study, Tang et al. [111] developed a numerical method to calculate elastic modulus of 316 SS lattice structures made with BJ technology. The method, based on equating the elastic strain energy of a heterogeneous representative volume element with the elastic strain energy of homogeneous material, was successfully validated with samples subjected to compressive and three-point bending tests. Lattice samples were fabricated following Chen and Zhao [59] recommended parameters obtained from DoE and ANOVA analysis for process optimisation.

Obtained elastic modulus results, shown in Figure 15, were lower compared with other parts fabricated with other MAM technologies like PBF-L or PBF-EB, due to the inner porosity of BJ process that left lattice walls less densified. Also, as fabrication process was designed to minimise part shrinkage, density of the green part does not increase substantially during sintering process. This can be appreciated in Figure 16. However, as it was said before, this could be an advantage for tissue engineering applications. Those

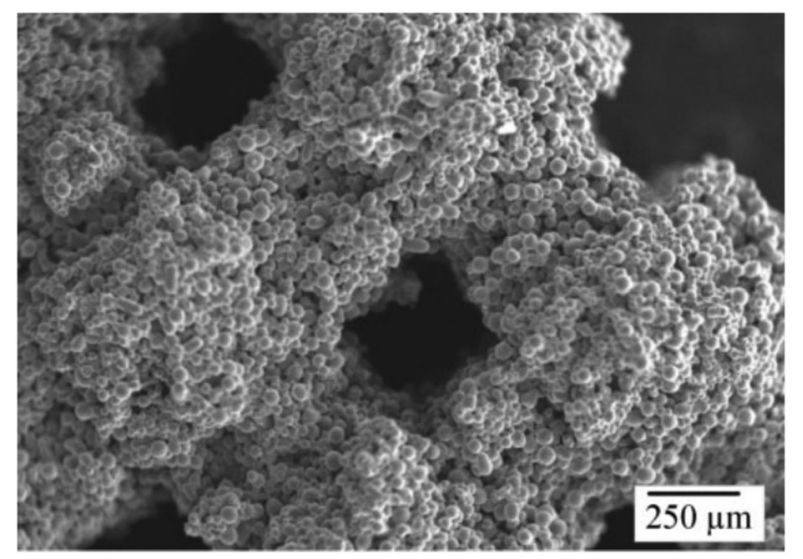

Figure 16. SEM image of a lattice structure fabricated with 316 SS in BJ, where wall porosity is easily appreciated [111]. micropores on lattice struts enhance the nutrient diffusion during the cell culture process.

Other attempts to fabricate metallic cellular materials was made by Williams et al. [79], from chemical reduction of metallic oxide precursors. In this case, iron oxide, nickel oxide, cobalt oxide and metallic molybdenum powders were mixed in order to obtain maraging steel after reduction and sintering of printed parts. Spray-dried $30 \mu \mathrm{m}$ granules were created with PVA and 1-5 $\mu \mathrm{m}$ particle size oxide powders, and a PVA solvent was used instead a binder in the printing process. Printed parts oxides were reduced at $850^{\circ} \mathrm{C}$ for $6 \mathrm{~h}$ and then were sintered at $1300^{\circ} \mathrm{C}$ for $3 \mathrm{~h}$. Complete reduction of the oxides led to maraging steel, with a relative density of $81 \%$ and $9 \%$ of open porosity, with $45 \%$ or linear shrinkage.

Although controlling part porosity for certain applications may in fact be of great interest, obtaining highdensity parts is most probably the principal handicap of binder jetted parts. To this aim, infiltrating the part with another metal with a low melting point is the most common method. However, some other techniques are currently being studied towards reaching fully densified parts, like nanoparticle jetting or sintering aid addition.

One of these attempts for improving part final density was studied by Do et al. [74]. In this case, three different boron-based sintering additives (pure B, BC and $\mathrm{BN}$ ) were mixed with 316 and 420 stainless steel bimodal particle size distribution powders. Cubic samples were printed and sintered at different temperatures and with different additive weight ratios, in order to optimise the part manufacturing process to the lowest sintering temperature and lowest additive content along with highest densification and lowest shrinkage levels.

Among the performed first attempts of experiments carried out at $1250^{\circ} \mathrm{C}$ in $\mathrm{Ar}$ atmosphere, the mix of 420 SS (30 and $6 \mu \mathrm{m}$ average particle size powders in 60:40 weight ratios) which has $0.5 \%$ of Boron Nitride as additive reached the highest relative density of $95.63 \%$. Sintering with $0.5 \% \mathrm{~B}$ or $\mathrm{BC}$ resulted in the extensive 
liquid formation and thus shape distortion while density did not experience a substantial increase. It was also observed that, higher sintering temperatures do not improve substantially the density but generate more distortion. On the other hand, surface quality experienced substantial enhancement reaching $\mathrm{Ra}$ of $3.72 \mu \mathrm{m}$, compared with the $\mathrm{Ra}$ of $18.46 \mu \mathrm{m}$ obtained with just 420 SS powder of an average particle size of $30 \mu \mathrm{m}$. Additionally, sample density was increased by sintering in vacuum furnace, reaching near $99 \%$ without appreciable shape distortion. Accomplished hardness measurements conclude that produced parts have attained same hardness values that the same material produced by traditional methods.

Since the oxidation is proportional to the total surface area of the particles, the use of very fine 316 SS particles (batches with average particle sizes of 14 and $4 \mu \mathrm{m})$ did not help reaching densities as high as in 420 SS samples. During the binder burnout cycle, the surface of 316 SS was extensively oxidised. However, looking at the results, full densifications in both martensitic and austenitic stainless steels may be reached with the correct tuning of $\mathrm{BJ}$ process and using reducing sintering atmospheres.

Following on with sintering aids matter, Yongha Kim et al. [77,102] investigated the effect of Silicon Nitride $\left(\mathrm{Si}_{3} \mathrm{~N}_{4}\right)$ sintering additives to 420 stainless steel powder; $35 \mu \mathrm{m}$ mean particle size steel powder was used along with $2 \mu \mathrm{m}$ mean size silicon nitride particles, mixed in different weight ratios. L-shaped and rectangular-shaped samples were printed to analyse dimensional changes and tensile properties after sintering. Samples were sintered at different temperatures and sintering times. Results show that part density increases with the increase of $\mathrm{Si}_{3} \mathrm{~N}_{4}$ content and increase of sintering temperature, due to liquid sintering mechanism. However, exceeding $12.5 \mathrm{wt}-\%$ of $\mathrm{Si}_{3} \mathrm{~N}_{4}$ leads to highly distorted final parts. Authors determine that the optimal experimental factors under the point of view of density, shape conservation capability and mechanical properties were $12.5 \mathrm{wt}-\%$ $\mathrm{Si}_{3} \mathrm{~N}_{4}$ content and sintering at $1225^{\circ} \mathrm{C}$ for $6 \mathrm{~h}$. Obtained densification of those parts was $95 \%$, with a volumetric shrinkage near to $45 \%$ and modulus of elasticity close to $200 \mathrm{GPa}$.

Other attempts towards the full densification of SS parts were made exploring the effect of nanoparticles. Two preliminary studies have been performed by Elliott et al. [75,76]. In the first one, SS 316L nanoparticle suspension was deposited on top of pre-sintered SS 316L binder-jet puck samples, and then totally sintered. EG and DEG water-based binder with different $\mathrm{pH}$ and polarity were designed to analyse the nanoparticle dispersion and carrying capabilities. Results showed that pre-sintered sample acted as a filter, piling nanoparticles on the top surface of the sample. Additionally, the same composition of both nanoparticles and base powder do not allow to detect properly the location of nanoparticles within the sample. For this reason, a second attempt was carried out using 420 SS base powder and pure copper nanoparticles, in this case using proprietary binder of ExOne $^{\bullet}$ as nanoparticle carrier. Different percentages of the voids present in 420 SS packed powder were filled adding different suspension quantities in order to explore the effects of concentration of nanoparticles within base powder. A significant foaming occurred in samples with high nanoparticle concentration and was hypothesised that nanoparticles may block solvent vapour to scape during curing of samples. Figure 17 shows SEM images of different $\mathrm{Cu}$ nanoparticle concentrations. It has been observed that nanoparticles act as an aid for sintering steel particles and could potentially increase part densification while reducing shrinkage. However, further studies should be performed in order to understand better the foaming phenomena, and also to determine optimum nanoparticle size and void fill fractions.

Carbon black nanoparticle suspension was also successfully tested to locally increase carbon content in tool steels. Godlinski et al. [97] used a D50 $22 \mu \mathrm{m}$ 420 steel powder for building $20 \mathrm{~mm}$ height cubes. Carbon black ink was progressively added to the binder during the 3DP process, in order to gradually increase the carbon content in the printed parts. Samples sintered under vacuum at $1350^{\circ} \mathrm{C}$ showed significant differences between the low carbon and high carbon content areas. The addition of $0.3 \%$ carbon black led to a $9 \%$ increased density, as well as to a significant increase of grain and pore growth. Additionally, geometrical distortions were reported due to the shrinkage difference between the two areas of the samples: 17\% linear shrinkage in high carbon content area and 10\% in the low carbon content area.

In further work, Godlinski and Veltl [112] confirmed the suitability for fabricating highly dense M390 and M2 tool steels with Binder Jetting. Although relatively large particle size powders were used $(<150 \mu \mathrm{m})$ in both alloys, liquid phases during sintering promote near-full densification of the samples (99\% relative density). Additional different heat treatments were successfully tested for tailoring the hardness of M390 alloy (from 50 HRC to $65 \mathrm{HRC}$ ). Additionally, an as sintered hardness of 40 HRC was obtained for M2 steel. Regarding surface quality, low surface roughness values were achieved in as sintered M2 steel $\left(9 \mu \mathrm{m} R_{a}\right)$ despite the used coarse particle sizes, thanks to the liquid phase sintering. Thus, a great potential of further improvement is expected with finer powders and/or additional post processing.

Doyle et al. [103] used $30 \mu \mathrm{m}$ mean particle size powder and a Tin Bronze infiltrant in order to achieve full densification. Experimental procedure was performed to analyse the effect of layer thickness in final 


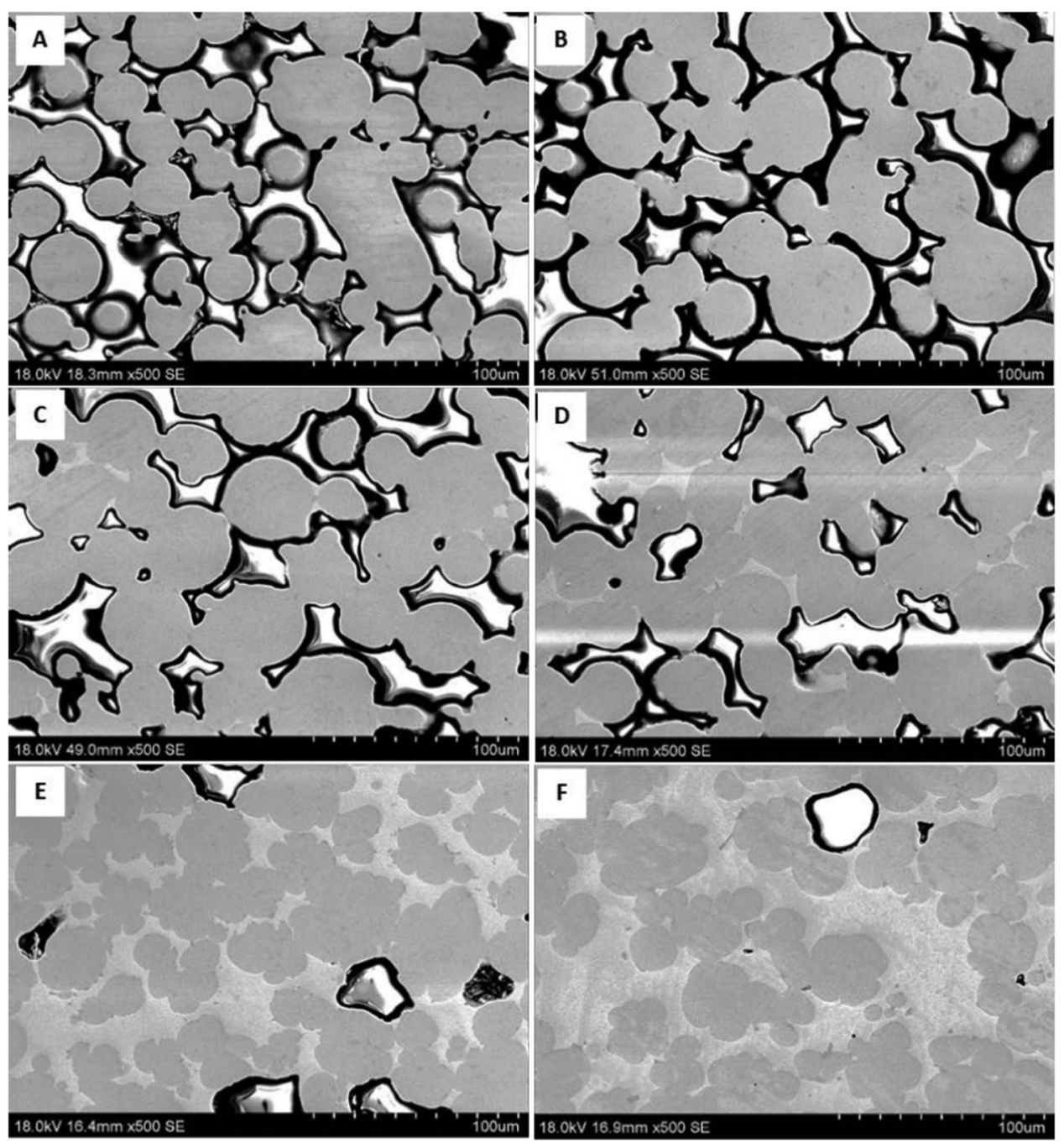

Figure 17. SEM images of sintered 420 SS samples with different targeted void percentages of Cu nanoparticles (a) $4 \%$, (b) $7 \%$, (c) $10 \%$, (d) $20 \%$, (e) $40 \%$ and (f) $70 \%$ [76].

part properties onto tensile test samples fabricated in different orientations; 50, 100 and $200 \mu \mathrm{m}$ layer thicknesses were selected as experimental parameters. Results show a strong effect of layer thickness on the mechanical properties of final parts, that is, while layer thickness increases, yield and ultimate tensile strength decrease (Figure 18). The high bronze content

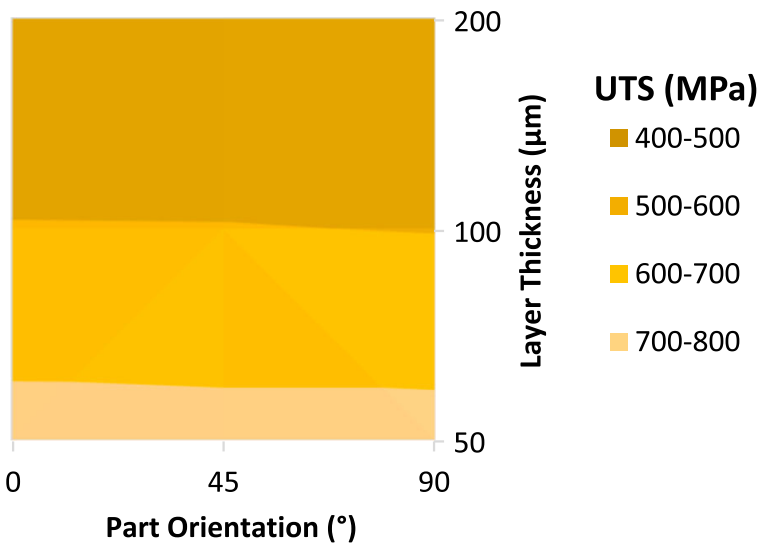

Figure 18. UTS contour plot of different 420 SS infiltrated samples in function of orientation and layer thickness [103]. (up to $60 \%$ in volume depending on the layer thickness) makes the material behave like a liquid phase sintered composite. Also, results show that there is not a significant mechanical property change between parts with different orientations.

A rapidly solidified high carbide and boride content iron powder were used by Cordero et al. [78] along with bronze infiltration to create high strength and high hardness net-shaped parts. This kind of alloys, also known as amorphous or glass metals, are designed to precipitate stable metal carbides and borides to prevent grain growth. Sintered and bronze infiltrated cylindrical parts were fabricated for comparison purposes. Results show that infiltrated parts had a transverse rupture strength of $570 \mathrm{MPa}$, almost four times higher $(130 \mathrm{MPa})$ than sintered material. Also, $11 \mathrm{GPa}$ micro $\mathrm{HV}$ hardness was reached in infiltrated parts, approximately $3 \mathrm{GPa}$ higher than the hardness of quenched high strength tool steels. The volume fraction of bronze was 0.35 and the density of final part reached $98 \%$. Also, it is worth mentioning that the low shrinkage obtained permits dimensional control to fabricate complex net-shaped 


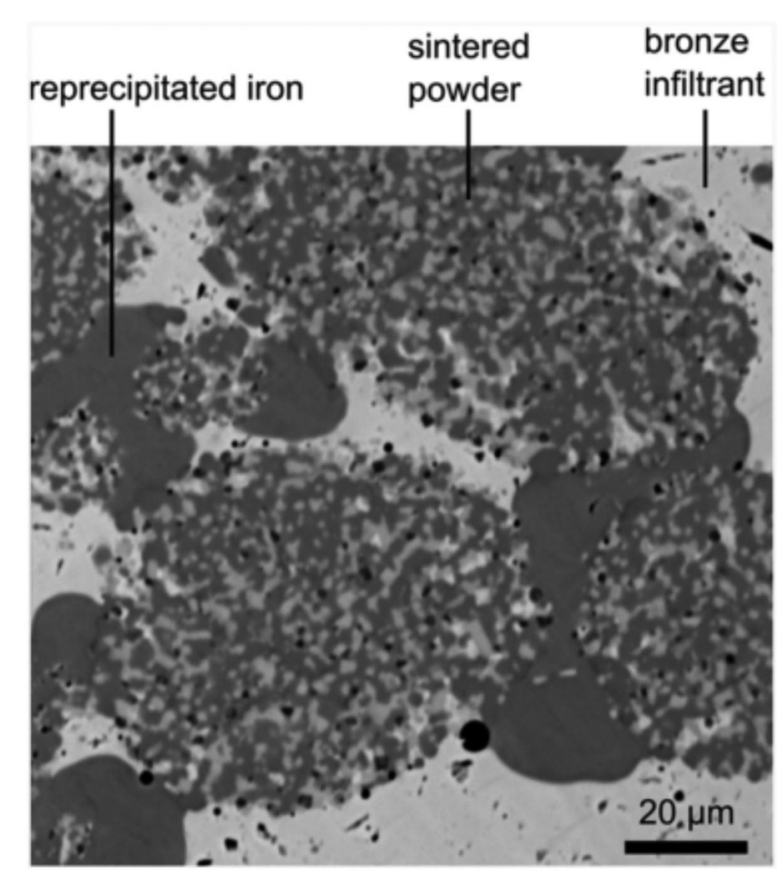

Figure 19. Precipitated iron due to dissolution within molten bronze infiltrant [78].

parts. Few issues were found through experimentation due to the dissolution of ferrite within molten bronze that then precipitates as pure $\alpha$-Fe, causing brittle fracture behaviour (Figure 19). Authors recommend this phase to be avoided reducing infiltration cycle time.

On another note, 316L SS was also explored to manufacture metallic antennas for millimetre and submillimetre wavelength applications, along with $\mathrm{Cu}$ 15Sn bronze fabricated via SLM. Bing Zhang et al. [113] analysed the surface roughness of as printed and sintered part, gold electroplated part and of micromachined part. The measured average roughness of tested surfaces was $12.89,4.64$ and $7.82 \mu \mathrm{m}$, respectively. However, obtained average surface roughness of micromachined $\mathrm{Cu}-15 \mathrm{Sn}$ antenna fabricated with SLM has a value of $0.25 \mu \mathrm{m}$, thus this material and process were chosen for further developments. This is also due to the easier machinability of bronze comparing to 316L SS.

\section{Nickel-based alloys}

In the same way than stainless steels case studies, one of the main R\&D streams in nickel-based superalloys is to reach the full density with $\mathrm{BJ}$-printed parts. Mostafaei et al. $[17,36,82]$ carried out some experimentations with the objective to analyse the densification, shrinkage and mechanical properties of Inconel 625 alloy. To this aim, different powder feedstock, like water or gas atomised, and different sintering temperatures range from 1200 to $1300^{\circ} \mathrm{C}$ were tested in a 4-h hold up time, while printing parameters were fixed for all experimentations. Also, some samples were post heat-treated to analyse the ageing and evolution of microstructure and material properties.

Differential scanning calorimetry was set at $1280^{\circ} \mathrm{C}$ as the optimal sintering temperature [82] for 16-53 $\mu \mathrm{m}$ size GA powder. With temperatures below this value, highly porous samples were obtained, with irregular interconnected porosity that worsens fatigue life and tensile strength. With high sintering temperatures $\left(1290\right.$ and $1300^{\circ} \mathrm{C}$ ), pore coarsening phenomena occurs, leading to bigger sized pores and in some cases lower final density. The obtained average grain size increases, decreasing the mechanical properties of samples. The obtained densification for $1280^{\circ} \mathrm{C}$ in a vacuum environment was $99.6 \%$ with a volumetric shrinkage of $18.7 \%$. Sintered microstructure shows a precipitation of $\mathrm{Nb}, \mathrm{Cr}, \mathrm{Mo}$ and $\mathrm{W}$ carbides and intermetallic phases, probably liquid phase formed, during sintering and related to the presence of $\mathrm{C}$ and $\mathrm{O}$ residuals. Ultimate tensile strength (UTS) of $612 \mathrm{MPa}$, yield strength (YS) of $327 \mathrm{MPa}$ and fracture strain of $40.9 \%$ was measured from the samples, similarly to as cast 625 alloy parts.

Further works [17,36] compared gas (D50 $30.8 \mu \mathrm{m}$ ) and water (D50 $32.5 \mu \mathrm{m}$ ) atomised samples, showing lower mechanical properties in samples printed with WA powder, due to higher pore percentage. Nearfully densified parts (99.2\%) were obtained with $1285^{\circ} \mathrm{C}$ sintering with GA powders, reaching $644 \mathrm{MPa}$ UTS, $376 \mathrm{MPA}$ YS, 213 HV0.1 hardness and $47 \%$ elongation at break. After ageing treatment at $745^{\circ} \mathrm{C}$ for $20 \mathrm{~h}$, precipitation of intermetallic phases and carbides (M23C6, MC, M6C, $\gamma^{\prime}, \gamma^{\prime \prime}, \delta$, Laves) was observed and consequently mechanical properties were increased reaching $718 \mathrm{MPa}$ UTS, $394 \mathrm{MPa}$ YS and 327 HV0.1 hardness, with a decrease of the elongation at break to $29 \%$. Also, WA and GA samples showed quite different microstructure evolution. While WA samples did not reach full densification and formed huge carbide and oxide precipitates with $\mathrm{Cr}$-, $\mathrm{Nb}$ - and Mo-depleted zones, GA reach near-full densification with small amounts of fine precipitates and no depletion zones.

The effect of solutioning and ageing heat treatments on already sintered dense part microstructure has been afterwards analysed [114,115]. Parts solutionised at $1150^{\circ} \mathrm{C}$ for $2 \mathrm{~h}$ and aged at $750^{\circ} \mathrm{C}$ for $60 \mathrm{~h}$ exhibited higher hardness and yield stress than parts made from MIM or casting processes, with the expected different phases of 625 alloy appearing in its microstructure.

With all this background experimentation accomplished, Mostafaei et al. [83] fabricated near-full density Inconel 625 partial denture framework with controlled shrinkage. Printer parameters were set up like in previous studies. Samples were then sintered embedded in alumina powder in a vacuum chamber at $1285^{\circ} \mathrm{C}$ for $4 \mathrm{~h}$. Densities and overall obtained properties coincide with previous research work $(>99 \%$ 
densification). The average dimensional change measured is of $15 \%$. Compared with EBM, which produces near-full density parts and a stress-relief postprocessing is required, $\mathrm{BJ}$ can provide tailored porosity parts $(0-40 \%)$ and more customisable features and properties for this kind of applications, also without the need of support structures for complex shapes or overhangs.

Some results regarding fatigue behaviour and surface roughness showed that $\mathrm{BJ}$ is a potential alternative to conventional manufacturing processes, after a proper sintering and surface treatments [116]. The average surface roughness measured from stylus profilometry of as sintered 625 sample was $R_{a}=1.10 \pm$ $0.16 \mu \mathrm{m}$ and decreased to $R_{a}=0.38 \pm 0.16 \mu \mathrm{m}$ after grinding surface treatment. There was a significant surface roughness reduction that indeed influences the fatigue life improvement in one order of magnitude. Moreover, the fatigue life of grinded BJ parts surpassed the runout cycle conditions $\left(10^{7}\right)$ at higher stress levels than casted parts and with stress ratio of $R=-1$, that promote lower fatigue life, comparing with the $R=$ 0.1 of casted parts. The elimination of the 'deep valleys' present in as-sintered parts that act as stress concentration and the mechanical hardening of part surface were reported to be the main causes of fatigue life improvement.

Sicre-Artalejo et al. [106] studied the effectiveness of HIP process to reach full density for 3DP Inconel 718

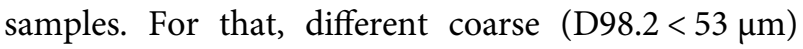
and fine $(\mathrm{D} 90<21.8 \mu \mathrm{m})$ powder blends were tested in different $\mathrm{BJ}$ devices using different commercial binders. A huge influence of binder and printing device on sample's sinterability, microstructure and as-sintered density was found. Sintering at $1290^{\circ} \mathrm{C}$ in high vacuum during $2 \mathrm{~h}$, with a heating rate of $5 \mathrm{~K} \mathrm{~m}^{-1}$, gave the highest densities for powder blend containing a $20 \mathrm{wt}$ \% of fine powder. Nevertheless, there was not any influence of binder or used particle size after HIPing process. All the samples reached full density under an HIP process at $1200^{\circ} \mathrm{C}$, with $206 \mathrm{MPa}$ pressure in Argon atmosphere for $3 \mathrm{~h}$. Therefore, the HIP postprocess may extend the range of suitable powders, machines and binders to be used, as they may not influence part density at the end.

Turker et al. [38] tested Inconel 718 alloy powder in BJ to analyse obtained sample properties changing layer thickness and sintering temperatures. Parts sintered below $1260^{\circ} \mathrm{C}$ showed high amount of porosity. Also, increasing printing layer thickness decreased the obtained sample densification, but it was only noticeable for low sintering temperatures as shown in Figure 20. For higher ones, density variation between different samples was almost negligible. From the microstructural point of view, SEM images of $1260^{\circ} \mathrm{C}$ sintered samples did not show any precipitates, while samples sintered at $1280^{\circ} \mathrm{C}$ showed some Nb-rich $\gamma^{\prime \prime}$ precipitates within grains and grain boundaries, desirable for alloy hardening. Increasing sintering temperature has led to precipitate dissolution along the grains leaving some pits. For this reason, authors have set $1280^{\circ} \mathrm{C}$ as recommended sintering temperature. The obtained densification and linear shrinkage for this sintering temperature were $98 \%$ and $19.5 \%$, respectively.

Due to the lack of knowledge about the relation between feedstock properties, process parameters and sintering kinetics in BJ printing, Nadwana et al. [84] documented the role of powder feedstock with sintering kinetics in solid state (SSS) and SLPS) along with empirical models. To this aim, 7, 21 and $70 \mu \mathrm{m}$ average size Inconel 718 powders from different suppliers were used and sintered at different temperatures; 7 and $70 \mu \mathrm{m}$ powder samples were not tested beyond $1290^{\circ}$ $\mathrm{C}$ due to collapse of the samples for the excessive liquid phase. The chemical composition differences and PSD between feedstock lead to different sintering kinetics and phase transformations. The authors remark the extreme importance of knowing feedstock chemistry to set up appropriate sintering parameters. Using Thermocalc software, the liquid phase at $1290^{\circ} \mathrm{C}$ for 7 and

\section{Density of Inconel 718 samples}

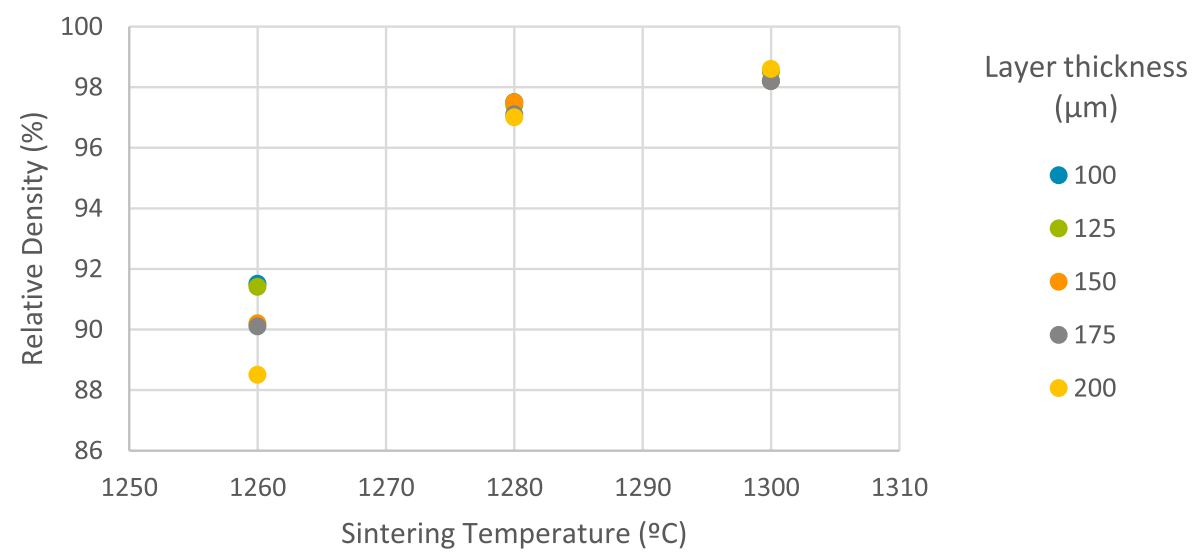

Figure 20. Sintered density dependence on build up layer thickness. Adapted from [38]. 
$70 \mu \mathrm{m}$ powders were estimated to be $35 \%$ and $40 \%$, respectively, while for $21 \mu \mathrm{m}$ one was $3 \%$ due to powder chemistry. Therefore, $99.9 \%$ densification was achieved in the first two mentioned powders and $92 \%$ in the third one. Also, depending on dominating sintering mechanisms (SSS or SLPS), different empirical mathematical models were built [117-119] in order to predict sintered shrinkage through material characteristics and sintering kinetics. Binder saturation was set to $80 \%$ for 7 and $21 \mu \mathrm{m}$ powders and to $70 \%$ for $70 \mu \mathrm{m}$ powder. Microstructurally, authors detect laves phase formation in $70 \mu \mathrm{m}$ powders SLPS sintered at $1290^{\circ} \mathrm{C}$ and $1330^{\circ} \mathrm{C}$, while in 7 and $21 \mu \mathrm{m}$ ones not. They assumed that higher binder saturation of the last two leads to higher residual carbon content that promotes MC carbide precipitation, while with lower carbon residuals, less desirable Laves and $\delta$ phases are more likely to precipitate.

\section{Titanium based}

Thanks to BJ AM process along with optimised sintering parameters, Titanium parts with tuned porosity can be fabricated. Bone tissues can easily grow inside the porous structure of a biocompatible alloy such as pure $\mathrm{Ti}$, maintaining a stable connection between the implant and the tissue. In this particular case, pure $\mathrm{Ti}$ ( $>98 \%)$ bone implant was successfully fabricated by Xiong et al. [80], with stiffness and compressive strength ranges similar to human bone(2-30 GPa and 130-180 MPa, respectively). In this case, 200 mesh $(<74 \mu \mathrm{m})$ titanium powder and 120 mesh $(<125 \mu \mathrm{m})$ aqueous PVA powder binder were mixed and used as feedstock. Polyvinylpyrrolidone was used as penetrator enhancer poured into the print-head supply chamber. Printed samples were sintered at different temperatures. Stiffness, strength and hardness of the samples increased with increasing sintering temperature, while porosity decreased.

xIn other work, porous cellular titanium structures were fabricated by Sheydaeian et al [51]. In this case, a powder blend was produced composed of $97 \mathrm{wt}-\%$ of Ti $(75-90 \mu \mathrm{m})$ and $3 w t-\%$ PVA $(<63 \mu \mathrm{m})$, and the effect of layer thickness in material properties was studied. 80 and $150 \mu \mathrm{m}$ layer thicknesses were selectively alternated during the printing of the samples in four different configurations. Results showed that porosity and shrinkage increases with the increase of layer thickness but obtained mechanical properties did not show significant changes $(2.9 \pm 0.5$ to $3.5 \pm 0.4) \mathrm{GPa}$ for Young's modulus and $(158 \pm 10$ to $175 \pm 27) \mathrm{MPa}$ for yield stress, obtaining values close to human cancellous bones.

Sheydaeian et al. combined both BJ and material extrusion AM technologies for Ti fabrication. Sacrificial polymer droplets were deposited periodically within a concrete number of $\mathrm{Ti}$ powder layers, in order to obtain structurally robust cellular structures with inner closed cavities [18]. Also, controlled porosity Ti parts were successfully developed by Sheydaeian et al. [19] with this hybrid AM technique. With selectively deposited sacrificial polymer droplets porous parts with mechanical properties similar to cancellous bones were obtained (Elastic modulus of $2.48 \pm 0.37$ to $3.55 \pm 0.49 \mathrm{GPa}$ and yield strength of $107.65 \pm$ 18.14 to $145.75 \pm 13.85 \mathrm{MPa}$ ). Analytical equations were suggested to estimate the porosity and stiffness and then compared to experimental results. The average error close to $5 \%$ in all the cases reveals the potential use of these equations to estimate porous part properties. Also, the author remarks the importance that sacrificial polymer droplets have on influencing process parameter role in part properties. Although between some samples the binder saturation level has a statistical influence in porosity variation, this influence became inestimable when sacrificial polymer droplets are used.

In a similar way, they replaced the polymer droplets by a slurry of Titanium Boride in order to fabricate Ti/ TiB2 periodic composites [120]. The obtained stiffness of fabricated samples increases up to $15.2 \%$ while small fraction of $4 \%$ ceramic reinforcement was added compared to samples made only with Ti powders.

Dilip et al. [81] developed a novel method to fabricate TiAl (titanium aluminide) porous parts directly from separate powders of $30 \mu \mathrm{m}$ Ti6Al4 V and $45 \mu \mathrm{m}$ $\mathrm{Al}$ mixed in equi-atomic portion and then reactive sintered. Results and micrographs (Figure 21) show the formation of the different intermetallic phases during the sintering process and the feasibility to use $\mathrm{BJ}$ as a manufacturing method. However, authors recommend a further detailed research on phase evolution, reaction kinetics and mechanical properties evaluation to scale up the process towards mass production. The good high-temperature strength and excellent corrosion resistance make porous $\mathrm{TiAl}$ alloys of great interest for aerospace and automotive sectors, as well as for high-temperature gas or liquid separation filters [121].

Stevens et al. [122] fabricated a Ti-6 Al-4V part in order to analyse which are the main effects in final part density differences. The density of the printed part varies from 50\% (in part edges) to 95\% (centre curve) relative density. This huge difference was reported to be likely due to two main effects. On one hand, the deposition of binder droplets may disrupt and distort the powder layer, droplet bouncing may affect to the quality of printed part edges, and the possible capillary migration of the binder parallelly along the powder layer may reduce part density along the part boundaries. Also, the low adherence of the edges may have an incrementally negative effect if the edges of consequent layers are located in the same position, rather than in different ones, such as in curved geometries. On the other hand, the presence of satellites in 

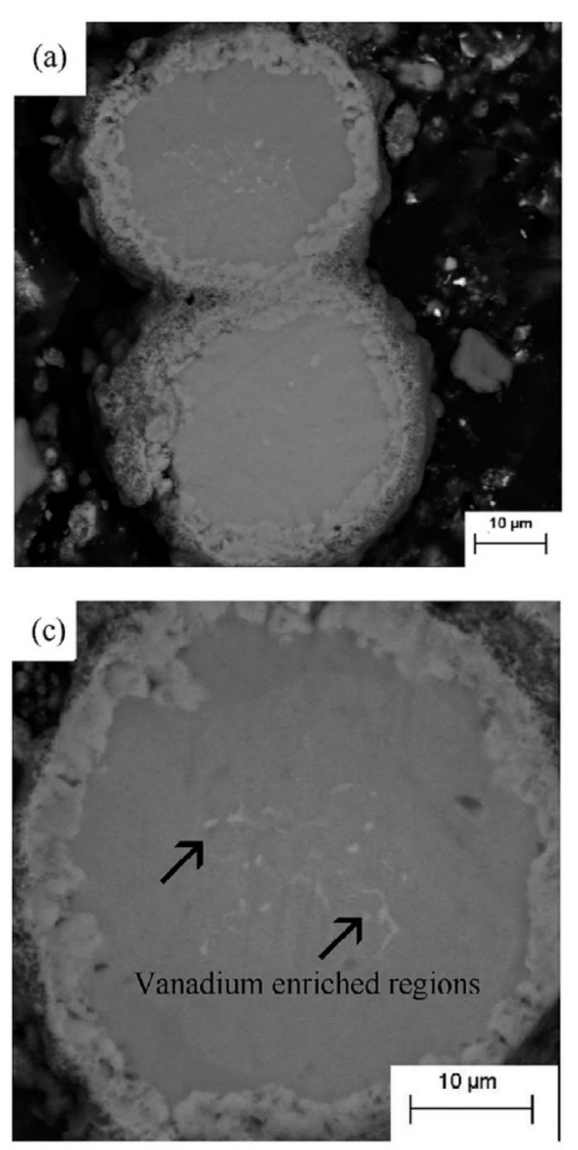

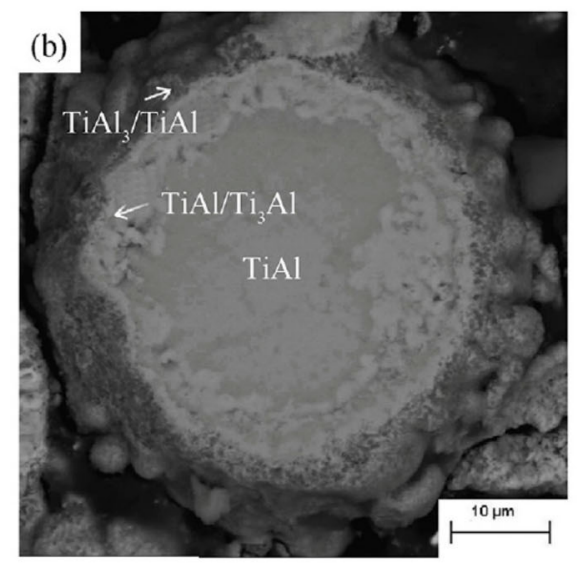

EDS spectrum corresponding to vanaduim rich regions

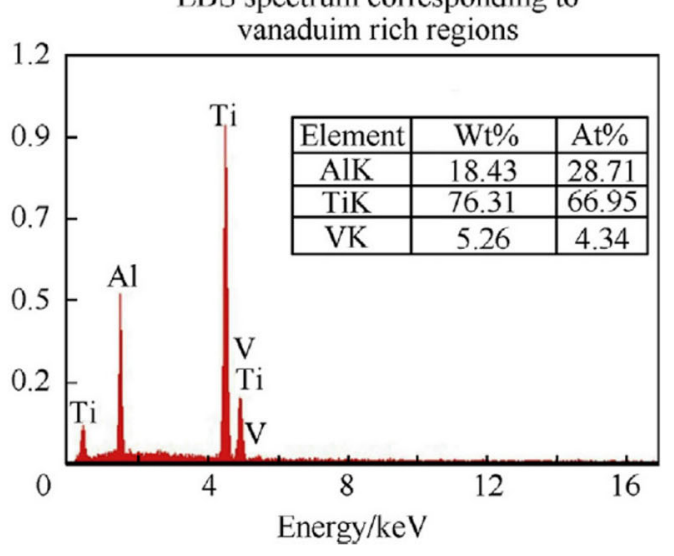

Figure 21. TiAl intermetallic alloy SEM and EDS spectra fabricated with Binder Jetting from separate Ti and Al powders [81].

coarse GA powder that decreases the packing efficiency, and the possible differences between the absorbed loads on printed slice core areas and the edges, may affect the part densification.

\section{Copper-based alloys}

Copper in BJ is an interesting metal since its main applications (thermal or electrical management systems) require complex shape parts. Because of its intrinsic properties (high thermal conductivity and high reflectivity), copper may have some complications to be fabricated via EBM or PBF technologies. Thus, BJ printing technology may be an alternative to manufacture complex-shaped copper parts. In this way, Bai et al. performed some explorations with pure copper powders [85], which were later on complemented testing bimodal mixtures [45,55] and HIP sintering [104] in order to increase copper parts densification.

In a first attempt [85], a coarse powder and two different fine powder batches obtained from different suppliers were used. Testing samples were fabricated under different printing conditions (layer thickness and binder saturation) and then sintered at different temperatures in different atmospheres $\left(\mathrm{Ar} / \mathrm{H}_{2}\right.$ with different hydrogen content ratios and in a vacuum). The purity of copper seemed to increase up to $97.3 \%$ in reducing atmospheres and also did the sintering density, reaching $78.2 \%$ relative density in highly reductive atmosphere for $2 \mathrm{~h}$ sintering at $1080^{\circ} \mathrm{C}$. Nevertheless, obtained tensile strength was $55.6 \%$ of the theoretical value [85], due to the huge grain growth and the low final densities.

In additional works, different bimodal powder mixtures were tried in order to increase powder packing density and thus final part density $[55,45]$. Four powder batches of $77,30,17$ and $5.5 \mu \mathrm{m}$ D50 particle sizes were used to create different mixtures to analyse their densification capabilities. It was found that both density and flowability, qualitatively calculated with the Hausner ratio, increased in bimodal mixtures. Bimodal mixtures with similar particle mean size of a monomodal powder $(30 \mu \mathrm{m}+5 \mu \mathrm{m}$ mixture compared to $15 \mu \mathrm{m}$ mean size powder) resulted in an increased sintering density, reaching $91.7 \%$ with a volumetric shrinkage of near $46 \%$, for samples sintered at $1080^{\circ}$ $\mathrm{C}$ for $2 \mathrm{~h}$ in pure hydrogen atmosphere. With coarser mixtures, i.e. $75 \mu \mathrm{m}+15 \mu \mathrm{m}$, despite apparent density increased, the final sintered density did not experience any improvement because of the rigid skeleton formed by larger particles which limited the contribution of fine powders to overall densification. Results demonstrate that an increase on part density can be achieved while shrinkage is reduced in bimodal mixtures. 

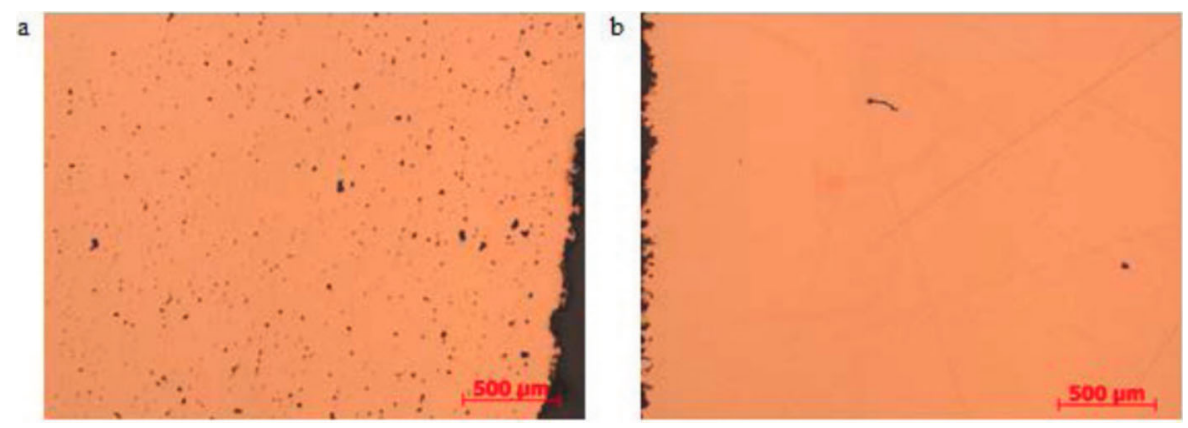

Figure 22. Copper sample micrographs showing porosity of the parts after sintering (a) and after HIP treatment (b) [104].

Finally, the effect of applying a HIP post-process was studied [104]. The powder mixture consisted of 30 and $5 \mu \mathrm{m}$ mean size batches, mixed in 73:27 weight ratios were used [45]. Parts were sintered at $1075^{\circ} \mathrm{C}$ for $3 \mathrm{~h}$ in pure hydrogen atmosphere and post HIP treated at $1075^{\circ} \mathrm{C}$ at $206 \mathrm{MPa}$ for $2 \mathrm{~h}$ in $\mathrm{Ar}$ atmosphere. HIP treatment increased the density of rectangular samples from $92 \%$ to $99.7 \%$ (Figure 22). However, an anisotropic shrinkage was observed between $X / Y$ axis (16\%) and $Z$ axis (20\%) due to non-homogeneous density of the green part. Authors remarked that the effect of HIP treatment in complex geometry parts could not be as effective as in simple geometries.

In further studies, the same sintering and HIP parameters were used to study the HIP effect on initial sintering density, mechanical properties, microstructure and porosity distribution [105]. The obtained maximum sintered density was $90.52 \%$, and after HIP process density $97.32 \%$ was reached, using the same bimodal mixture used in the previous study. These lower densities were attributed to inkjet nozzle clogging during printing stage, as well as to differences in powder quality. Measured tensile strength was $176 \mathrm{MPa}$, $80.16 \%$ of fully dense copper parts. Although HIP process closes porosity and thus improves part strength, resulting grain growth leads to lower strength, thus compensating the increase of mechanical resistance due to higher densification.

In recent studies, Bai et al. tried to replace the organic binder by copper nanoparticle suspension, in an adapted BJ process named as 'Binderless Jetting' by the authors. Replacing ordinary organic binders by nanoparticle suspensions may have some advantages [94], as mentioned in the previous section:

- No need of accurate and sophisticate sintering profiles for proper binder burn out and degassing.

- No debinding step required.

- Absence of binder carbon residuals that may affect final part properties.

Some theories and observations confirm that copper nanoparticles can generate sintering necks below $300^{\circ}$

C. Thus, with an overheating heater, sintering bonds can be created, shown in Figure 23, between each printing layer just heating up suspension jetted nanoparticles by the print-head, with 2 min interlayer heating at $260^{\circ} \mathrm{C}$.

Results show an $150 \%$ increased green part strength using a $140 \%$ saturated copper nanoparticle suspension, comparing with organic binder at $100 \%$ saturation. Nevertheless, the obtained sintered densities of nanoparticle bonded green parts were near 20\% lower than green parts fabricated with organic binder. Authors explained that still, sintering mechanisms using nanoparticles remain uncertain, stating that further research will be focused on analysing and improving densification using copper nanoparticle bonded green parts.

To reduce the inherent problems related to particle suspension; like inkjet nozzle clogging, particle sedimentation and surface oxidation, MOD inks can be an advantage as they are particle-free inks. MOD ink printed parts by Bai et al. [95] showed higher core densities than polymer binder printed ones. Nevertheless, due their insufficient green part strength, a large pore outer shell remains after the depowdering process with compressed air, resulting in a lower overall density than parts produced with polymeric binder. The use of a7.4 wt- $\%$ metallic content MOD ink at 150\% printing saturation, reduced the overall part shrinkage and its dependence to sintering temperature.

\section{MMCs and others}

MMCs are a family of advanced materials with low density, high specific strength, high specific modulus, high wear resistance and in some cases high thermal conductivity that can be used for a wide range of different applications. However, the uses of this kind of composites have been constrained due to their high cost and the limited possible geometrical configurations.

Snelling et al. [123] propose a novel method to fabricate cordierite (mixture of alumina, silica and magnesia) ceramic cores via $B J$ that then will be embedded in a metallic material with casting procedures. However, the weak mechanical bonding of metal-ceramic interface, and the high thermal shock ceramic core must 


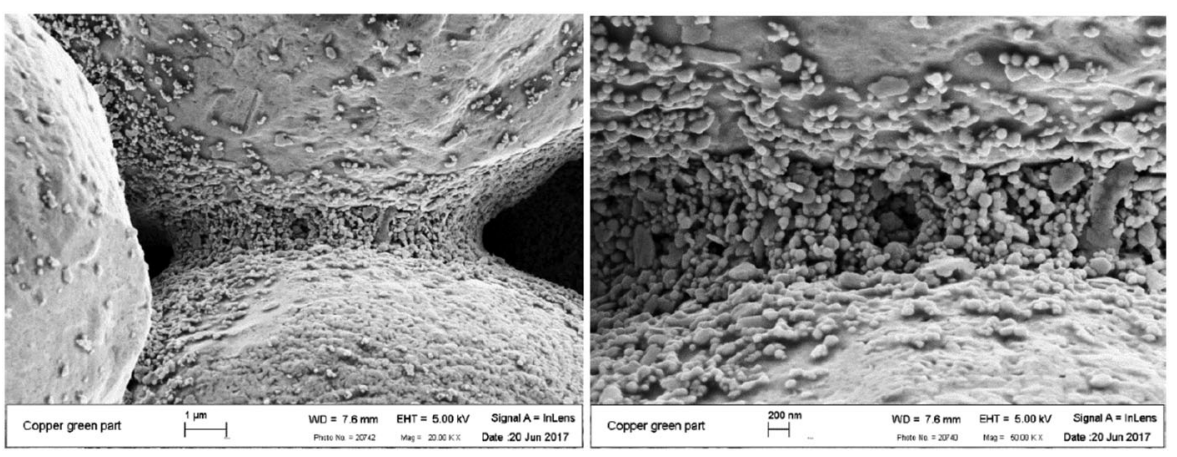

Figure 23. Nanoparticle bonding between copper particles in printed green parts [94].

withstand during metal casting, makes necessary to develop further research work to settle the process.

Other way to fabricate MMCs is to directly manufacture final parts from mixed metallic and ceramic precursor powders or via infiltration of metallic matrix after printing porous ceramic skeleton.

One of these trials is the novel complex-shape graded $\mathrm{TiC} /$ steel composites manufacturing method developed by Miriyev et al. [86]. $\mathrm{TiC}_{\mathrm{x}}$ green preforms were first fabricated, with graded carbon content in titanium carbide phase ( $x$ changing from 0.7 to 0.98 ). Then, these preforms were infiltrated with SAE1070 carbon steel in a vacuum furnace. After infiltration cycle, and due to thermodynamic considerations in which carbon is transferred both from $\mathrm{TiC}$ to steel and vice-versa, a microstructural gradient was obtained throughout the steel matrix from ferrite, in the region where the steel was in contact with titanium carbide of low carbon content $(x=0.7)$, to pearlite, in the region where the steel underwent interactions with stoichiometric titanium carbide $(x=0.98)$. After annealing and quenching treatments, a gradient from ferrite to martensite was obtained (Figure 24), achieving a hardness gradient from 700 to $1600 \mathrm{HV}$, that allows to develop new gradient tailored full dense parts for tooling, wear, aerospace and other fields of application.

$\mathrm{TiC}_{\mathrm{x}}$ graded powders were fabricated mixing $\mathrm{TiC}_{0.98}$ and pure $\mathrm{Ti}$ powders in appropriate ratios by ball milling. To synthetise $\mathrm{TiC}_{\mathrm{x}}$, first a 4 -h furnace cycle was performed at $1400^{\circ} \mathrm{C}$, and then the part was free infiltrated with steel at $1550^{\circ} \mathrm{C}$ for $15 \mathrm{~min}$. Then, fabricated samples were annealed at $900^{\circ} \mathrm{C}$ for $30 \mathrm{~min}$ and then oil quenched.

Enneti et al. [107] studied the viability of manufacturing MMC components with WC-12\%Co precursor powders with $\mathrm{BJ}$. The summarise that $\mathrm{WC} / \mathrm{Co}$ parts with good mechanical properties can be achieved with this technology. Using SLM/SLS technologies only 40 or $65 \%$ theoretical densifications can be achieved fabricating $\mathrm{WC} / \mathrm{Co}$, while BJ technology offers the opportunity to fabricate near-full density complex WC/Co parts.

In this study, feedstock powder was prepared mixing fine WC $(1.2 \mu \mathrm{m})$ and Co $(1.2 \mu \mathrm{m})$ powders with spray drying technology. Obtained WC- $12 \% \mathrm{Co}$

\section{Hardness gradient in function of $\mathrm{TiC}$ composition}

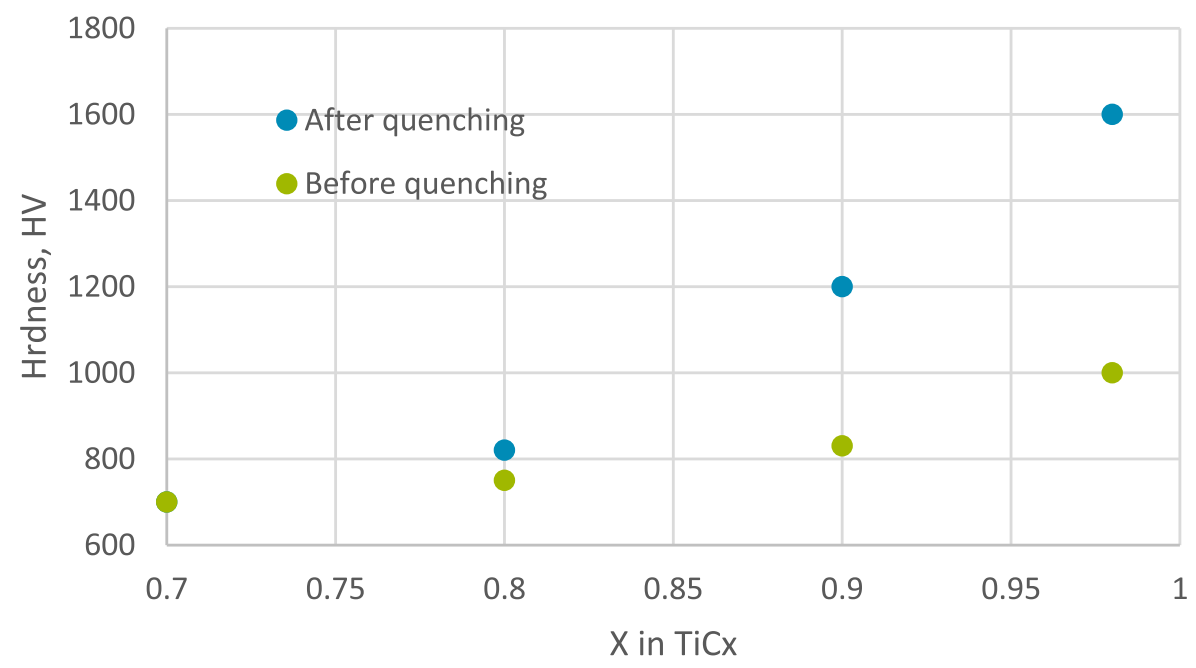

Figure 24. Hardness values of the composite layers as a function of titanium carbide composition before and after quenching. Adapted from [86]. 
powder exhibited an average particle size of $25 \mu \mathrm{m}$, along with spherical morphology and good flowability. Printed prismatic samples were cured and then debound in $\mathrm{H}_{2}$ atmosphere prior to sintering. After that, samples were sintered at different temperatures and in different atmospheres (vacuum and pressurised Ar at 265 psi). Finally, to compensate carbon loss, carbon correction cycle within methane gas was conducted at $800^{\circ} \mathrm{C}$.

Results showed a final density of $94 \%$ for parts sintered at $1465^{\circ} \mathrm{C}$ for $45 \mathrm{~min}$, with lightly anisotropic shrinkages (near $22 \%$ in $X Y$ axes and $24 \%$ in $Z$ ). For samples sintered under pressure atmosphere of $\mathrm{Ar}$ at $1485^{\circ} \mathrm{C}$ near $100 \%$ theoretical density was achieved, with shrinkages near to $23 \%$ in $X Y$ axes and up to $26 \%$ in $Z$. Authors remarked that with higher pressures, like the ones used in HIP processes, full density parts could be achieved with lower sintering temperatures. The obtained hardness and fracture toughness values were in line with conventionally produced parts, confirming the feasability of fabricating WC/Co parts with appropriate mechanical properties via BJ Figure 25.

Dense SiSiC ceramic composites were fabricated by Travitzky et al. [87] from $\mathrm{Si} / \mathrm{SiC} /$ dextrin powder blend. After printing and infiltrating with silicone, which acts as a transcient shape stabilizator, green samples were pyrolysed and then successfully infiltrated with liquid silicone. $19.5 \mu \mathrm{m}$ Si powder, $16.2 \mu \mathrm{m} \alpha$-SiC powder and $109 \mu \mathrm{m}$ dextrin powder were blended varying $\mathrm{Si}$ and $\mathrm{SiC}$ proportions while maintaining dextrin content, which acts as a binder when interacting with printer aqueous solution. Once samples were printed, they were infiltrated with silicon resin and then cured. After the pyrolszing process at $1000^{\circ} \mathrm{C}$ in nitrogen atmosphere, both dextrin and silicone leave a carbon and $\mathrm{Si}-\mathrm{O}-\mathrm{C}$ residues, respectively. Finally, samples were infiltrated with liquid $\mathrm{Si}$ at $1500^{\circ} \mathrm{C}$ for $2 \mathrm{~h}$ to create final SiSiC dense composites.
Results show that infiltrating a preceramic polymer leads to a reduction of the anisotropic shrinkage usually observed in $\mathrm{Z}$ direction. Mechanical properties of final samples are shown in Figure 26. Duckworth and Ondracek equations are used to calculate elastic modulus and bending stress of samples irrespective of porosity content. The obtained values match with 'rule of mixtures', which shows a linear relationship between phase percentage, mechanical properties and density (Figure 26). Additionally, microcellular lattice structures were printed to test near-net shaping capability and infiltration behaviour of liquid Si within complex-shaped part. Infiltration time strongly depends on part geometry; thus authors recommend radial infiltration procedures in order to reduce process time.

In the path of this study, Halbing and Singh [124] from the NASA tested samples fabricated with a similar process but also using $\mathrm{SiC}$ fibres as reinforcement. The main objective was to study the viability of $B J$ to fabricate non-metallic turbines for jet engines. They noticed a significative increase (near 40\%) in both strength and strain to failure.

Another interesting material for jet engine applications is titanium silicon carbide $\left(\mathrm{Ti}_{3} \mathrm{SiC}_{2}\right)$, due to its unique ceramic-metallic behaviour that combines high mechanical resistance, thermal shock resistance, high electrical and thermal conductivity, high oxidation resistance, high machinability, low hardness and high stiffness. Lorenz et al. [88] carried out some tests combining in one hand $\mathrm{BJ}$ technology with Cold Isostatic Pressing (CIP), and in the other BJ with Uniaxial Pressing (UP). Then, samples from both procedures were sintered at $1600^{\circ} \mathrm{C}$ for $2 \mathrm{~h}$ and characterised. CIP-ed samples were pressed at 35,150 and $180 \mathrm{MPa}$, and UP ones pressed under $765 \mathrm{MPa}$. Also, unpressed samples were fabricated for comparison purposes.

\section{Part relative density and hardness}

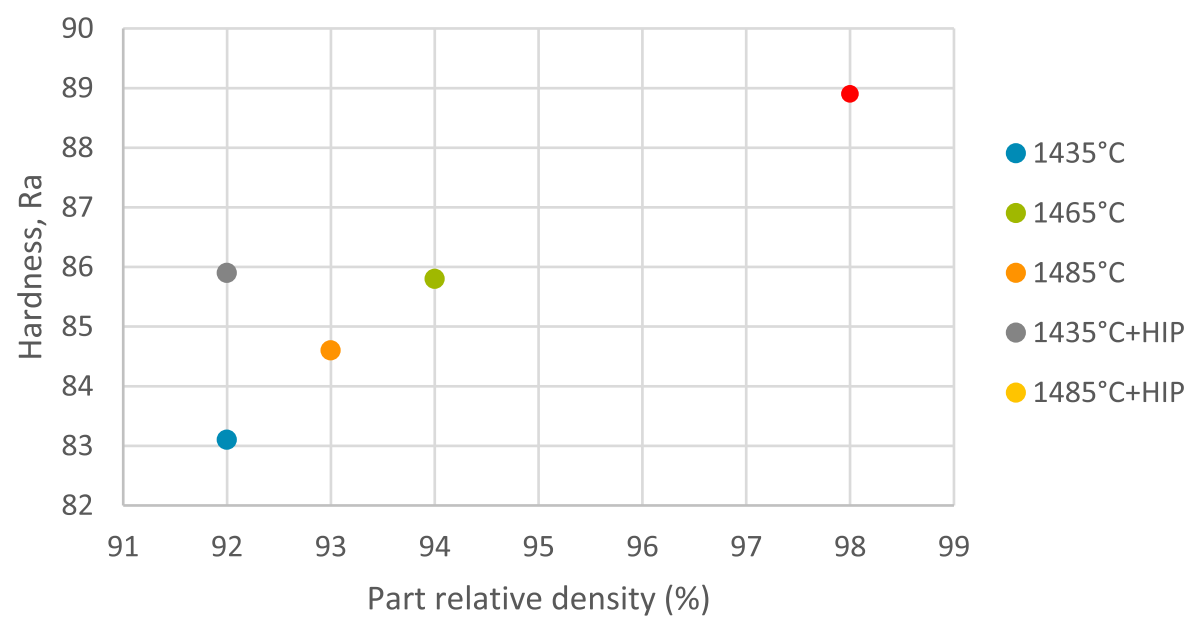

Figure 25. Tested part relative density and hardness as function of the sintering cycle. Adapted from [107]. 


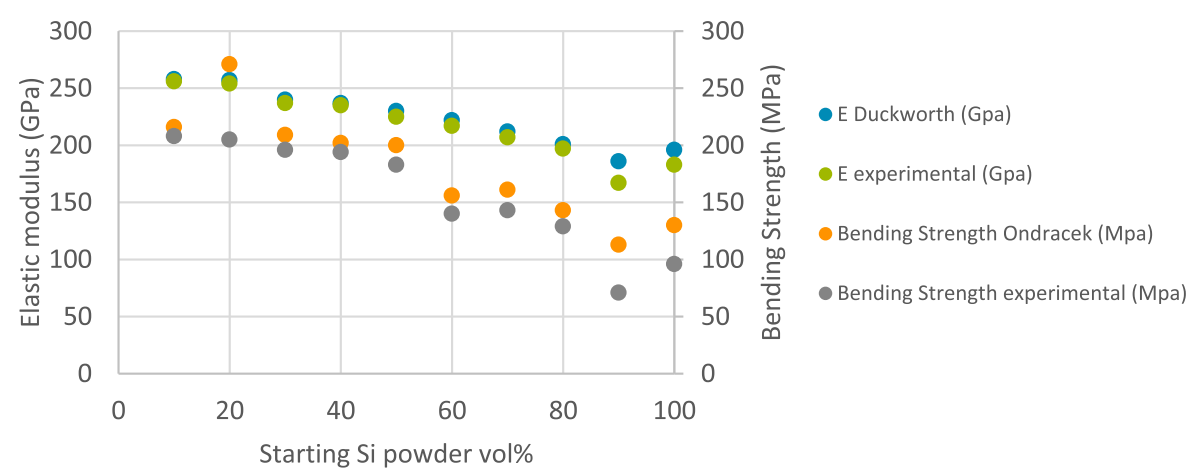

Figure 26. Calculated mechanical properties of SiSiC composites in function of starting powder Si-SiC content per cent [87].

The highest young modulus values were obtained from UP samples, 273-300 GPa, which are lower than fully dense part values predicted from literature of $320 \mathrm{GPa}$. Although stiffness and density increased with the pressure used before sintering, only UP samples experience an increase in flexural strength (3 GPa). CIP-ed samples flexural strength values remain like unpressed samples values (1 GPa), thus CIP may not be an optimal process to achieve higher strength. Nevertheless, these values are an order of magnitude higher than strengths obtained with other methods (260 MPa for synthetised $\mathrm{Ti}_{3} \mathrm{SiC}_{2}$ with reactive hot-pressing and $470 \mathrm{MPa}$ for bulk $\mathrm{Ti}_{3} \mathrm{SiC}_{2}$ with temperature fluctuation synthesis/hot pressing synthesis).

However, fully densified samples were not achieved for any of the UP samples. Despite authors did not mention the use of such compressing techniques may not be appropriate for manufacturing processes involving $\mathrm{BJ}$ technology. The reason resides in that the use of BJ technology makes sense to fabricate complexshaped parts, and both CIP and UP may not be suitable for this purpose.

Due to the flexibility of BJ and other AM technologies like material extrusion to be used with a wide variety of materials, Paranthaman et al. [125] explored the suitability of this manufacturing technologies to fabricate $\mathrm{NdFeB}$ magnets. Although there are many remaining subjects to be optimised and developed, those close to microstructure control and magnetic field alignment, a new design possibility for engine and electronic applications are opened. Also, the high cost and the strategic dependence of rare earths makes justify this technology in terms of material saves and waste reduction.

In a first attempt, a resin-coated isotropic $\mathrm{NdFeB}$ powder of $70 \mu \mathrm{m}$ average size was used to fabricate rectangle and ring near net-shaped parts [89]. After printing and curing process, the $46 \%$ density green samples were infiltrated with liquid urethane resin to improve their mechanical strength and surface finish. Measured intrinsic coercivity of printed samples match fits with the values of starting NdFeB powder, thus concluding that $\mathrm{BJ}$ process does not affect the magnetic properties of the feedstock.

In a further research, $\mathrm{NdFeB}$ isotropic magnets were successfully fabricated with binder jetting and infiltration processes [90]. To this aim, rare-earth low point melting alloys based on $\mathrm{Nd}$ and $\operatorname{Pr}(\mathrm{NdCuCo}$ and PrCuCo, respectively) were used as infiltrants. Results showed that intrinsic coercivity of magnets improved dramatically from 732 to $1300 \mathrm{kA} / \mathrm{m}$ (near $80 \%$ of increase), although remanence was slightly worse from 0.35 to $0.30 \mathrm{~T}$, since non-ferromagnetic infiltration alloys did not contribute to the net magnetisation, which is reduced after the infiltration process. However, mechanical strength and densification of bonded magnet were improved. Finally, authors remarked the optimisation need to increase the loading fraction, reduce porosity and minimise remanence loss.

\section{Summary}

An overview of BJ-MAM technology has been presented, with a special focus on raw material considerations, the process itself, the effect of parameters on the properties of fabricated parts and the state of the art of current studies based on different metal alloys.

Regarding raw materials, the main concern in $\mathrm{BJ}$ is the selection of a powder feedstock with an optimal balance between its processability during the printing stage and its sinterability. On the one hand, high flowability powders are usually the best suited for the $3 \mathrm{D}$ printing stage. Their spreadability will determine the homogeneity and quality of the powder bed, and hence reduce the variability in properties between parts from the same batch. Also, the probability of printing defects and rejected parts will be substantially reduced. On the other hand, high flowability is usually linked to coarser and narrower distributed powders which penalises sinterability and thus reduces the achievable densification level. To address this issue, bimodal powder mixtures, sintering aids or novel metal charged binder systems are being explored to 
increase part densification whilst maintaining an adequate flowability during the process. Additionally, the selection of a proper binder system, the binder droplet interaction with the powder bed, along with the binder drying step during the printing process (due to its direct influence on the interlayer quality and dimensional accuracy) are also critical issues in the BJ technology development $[52,53]$.

The sintering process enables the creation of a wide range of material configurations and the tuning of part properties; from fully dense parts [74,82], parts with pre-designed and controlled porosity $[15,110,111]$ to infiltrated parts with graded properties [86]. Due to the sintering process and the absence of thermal inputs during green part fabrication, the final as-manufactured parts show residual stress-free near-isotropic properties, which are difficult to attain using other metal AM technologies.

BJ technology offers the possibility to use almost any kind of particulate material as well as a broad range of particle sizes, as shown in the case studies presented in the previous sections. Nevertheless, recent studies are still focused on the preliminary aspects of the material, and more precisely focused on improving the final part density, which is currently a crucial issue of $\mathrm{BJ}$ technology.

To date, the relatively large amount of process steps and parameters involved in BJ metal parts fabrication, as well as a lack of complete understanding of the process, makes $\mathrm{BJ}$ a challenging $\mathrm{AM}$ technology. A greater level of expertise, R\&D investment as well as better developed qualification and certification is required as a basis for a widespread industry adoption [126]. Nevertheless, the increasing number of recently published research works, the near-future release of newer, more highly productive $\mathrm{BJ}$ machines [13] and the growing industry interest towards this technology, makes the future of BJ highly promising.

\section{Disclosure statement}

No potential conflict of interest was reported by the authors.

\section{Funding}

This work has been done within the ADDISEND project supported by the ELKARTEK program of the Basque Government [KK-2018/00115].

\section{Notes on contributors}

Asier Lores graduated in Aerospace Engineering from the Polytechnic University of Madrid (2016) with honorable mention for his final degree project on statistics and predictive wind power forecasting model. Master in Advanced Materials Engineering from UPV-EHU (2018), with an outstanding mark in his master thesis about the additive manufacturing of metal components by binder jetting. He is currently a researcher and $\mathrm{PhD}$ student in Binder Jetting additive manufacturing at Tecnalia. His main research areas are ceramic and metal powder processing, Binder Jetting additive manufacturing and process optimization.

Naiara Azurmendi Industrial Technical Engineer specializing in Industrial Chemistry (2005), Materials Engineer (2008) and Master in Polymeric Materials (2010) from the University of the Basque Country. Since 2007 she develops her research work in TECNALIA, developing various European and national R\&D projects related to the processing of metallic, ceramic and composite materials (polymeric and metallic matrix) by powder metallurgy and alternative heating techniques (microwave, radio frequency and induction). In recent years she has been conducting research projects in the development of Binder Jetting Additive Manufacturing for both metals and ceramics.

Dr. Iñigo Agote PhD in Chemical Sciences from the UPVEHU (1995). He has been working in TECNALIA since 1996 in the development of new materials and processes in powder metallurgy and additive manufacturing. Project Manager and head of the "materials for extreme conditions" research group. He has participated in a significant number of R\&D\&I projects both at National and International level, for different sectors like Machine Tooling, Space, Energy, tile industry, Biomedicine, Aeronautics, etc.... He has a great experience in materials and processes of ceramic, metallic and composites, as well as in the characterization or evaluation of their physical, chemical and mechanical properties. Author of 3 industrial patents and more than 15 national and international publications in specialized scientific journals.

Dr. Ester Zuza researcher and titular professor in Department of Mining-Metallurgical Engineering and Materials Science of the UPV-EHU since 2006. She has directed more than 5 Doctoral Thesis and participated in more than 30 national and international projects. He has attended more than 25 national and international conferences and has published more than 20 original research, giving rise to an $\mathrm{H}$ index of 11 . Her research lines are focused on bio, nano, polymeric and composite materials.

\section{ORCID}

Asier Lores (D) http://orcid.org/0000-0003-0873-2647 Iñigo Agote (D) http://orcid.org/0000-0001-5898-1866 Ester Zuza (D) http://orcid.org/0000-0002-8933-1986

\section{References}

[1] Hull CW. Apparatus for production of three-dimensional objects by stereolithography. US4575330 A. 1984.

[2] Baker R. Method of making decorative articles. 1,533,300, 1920.

[3] Greul M, Pintat T, Greulich M. Rapid prototyping of functional metallic parts. Comput Ind. 1995;28:2328.

[4] Wong KV, Hernandez A. A review of additive manufacturing. ISRN Mech Eng. 2012;2012:1-10.

[5] ASTM F2792-12a. Standard terminology for additive manufacturing technologies 1,2. 2013.

[6] Milewski JO. Additive manufacturing of metals. Springer Series in Materials Science. 2017; p. 258.

[7] Babu B, Sridhar Babu B. A critical review on recent research methodologies in additive manufacturing. Mater Today Proc. 2017;4(4):9049-9059. 
[8] Yang S, Tang Y, Zhao YF. A new part consolidation method to embrace the design freedom of additive manufacturing. J Manuf Process. 2015;20: 444-449.

[9] Nickels L. AM and aerospace: an ideal combination. Met Powder Rep. 2015;70(6):300-303.

[10] Javaid M, Haleem A. Additive manufacturing applications in medical cases: A literature based review. Alexandria J Med. 2018;54(4):411-422.

[11] Attaran M. The rise of 3-D printing: The advantages of additive manufacturing over traditional manufacturing. Bus Horiz. 2017;60:677-688.

[12] Sachs EM, Haggerty JS, Williams PA. Three-dimensional printing techniques. 5204055, 1993.

[13] Boris Hein S, Aumund-Kopp C, Barthel B. Binder Jet metal AM: process chain considerations when moving towards series production. Met Addit Manuf. 2018;4 (4):79-85.

[14] Zhang S, Miyanaji H, Yang L, et al. An experimental study of ceramic dental porcelain materials using a 3D print (3DP) process. Solid Freeform Fabrication Symposium. 2014; 991-1011.

[15] Vangapally S, Agarwal K, Sheldon A, et al. Effect of lattice design and process parameters on dimensional and mechanical properties of binder Jet Additively manufactured stainless steel 316 for bone scaffolds. Procedia Manuf. 2017;10:750-759.

[16] Qian M. Metal powder for additive manufacturing. JOM. 2015;67(3):536-537.

[17] Mostafaei A, Hughes ET, Hilla C, et al. Data on the densification during sintering of binder jet printed samples made from water- and gas-atomized alloy 625 powders. Data Br. 2017;10:116-121.

[18] Sheydaeian E, Sarikhani K, Chen P, et al. Material process development for the fabrication of heterogeneous titanium structures with selective pore morphology by a hybrid additive manufacturing process. Mater Des. 2017;135:142-150.

[19] Sheydaeian E, Toyserkani E. Additive manufacturing functionally graded titanium structures with selective closed cell layout and controlled morphology. Int J Adv Manuf Technol. 2018;96(912):3459-3469.

[20] Slotwinski JA, Garboczi EJ. Metrology needs for metal additive manufacturing powders. JOM. 2015;67 (3):538-543.

[21] Benson JM, Snyders E. The need for powder characterisation in the additive manufacturing industry and the establishment of a national facility. South African J Ind Eng. 2015;26(2):104-114.

[22] Bochuan Liu RH, Wildman R, Tuck C, et al. Investigation the effect of particle size distribution on processing parameters optimisation in selective laser melting process. Solid Freeform Fabrication Symposium. 2011: 227-238.

[23] Elliott AM, Nandwana P, Siddel D, et al. A method for measuring powder bed density in binder jet additive manufacturing process and the powder feedstock characteristics influencing the powder bed density. Solid Freeform Fabrication Symposium. 2016: 10311037.

[24] Oh J-W, Nahm S, Kim B, et al. Anisotropy in green Body bending strength due to additive direction in the binder-Jetting additive manufacturing process. Korean J Met Mater. 2019;57(4):227-235.

[25] German RM. Particle packing characteristics. 1989.

[26] ASTM B 527-15. Standard test method for tap density of metal powders and compounds; 2015.
[27] Santomaso A, Lazzaro P, Canu P. Powder flowability and density ratios: the impact of granules packing. Chem Eng Sci. 2003;58:2857-2874.

[28] ASTM B923 - 16. Standard test method for metal powder skeletal density by helium or nitrogen pycnometry. Subcommittee B09.03, 2016.

[29] Viana M, Jouannin P, Pontier C, et al. About pycnometric density measurements. Talanta. 2002;57:583593.

[30] Sohn HY, Moreland C. The effect of particle size distribution on packing density. Can J Chem Eng. 1968;46(3):162-167.

[31] Lu G, Third JR, Müller CR. Discrete element models for non-spherical particle systems: from theoretical developments to applications. Chem Eng Sci. 2015;127:425-465.

[32] Höhner D, Wirtz S, Scherer V. A study on the influence of particle shape on the mechanical interactions of granular media in a hopper using the discrete element method. Powder Technol. 2015;278:286-305.

[33] Byholm T, Toivakka M, Westerholm J. Effective packing of 3-dimensional voxel-based arbitrarily shaped particles. Powder Technol. 2009;196:139-146.

[34] Dong K, Wang C, Yu A. A novel method based on orientation discretization for discrete element modeling of non-spherical particles. Chem Eng Sci. 2015;126:500-516.

[35] Jia X, Gan M, Williams RA, et al. Validation of a digital packing algorithm in predicting powder packing densities. Powder Technol. 2007;174:10-13.

[36] Mostafaei A, Toman J, Stevens EL, et al. Microstructural evolution and mechanical properties of differently heat-treated binder jet printed samples from gas- and water-atomized alloy 625 powders. Acta Mater. 2017;124:280-289.

[37] Popovich A, Sufiiarov V. Metal powder additive manufacturing. In: New trends in 3D printing. 2016;3: 215-236.

[38] Turker M, Godlinski D, Petzoldt F. Effect of production parameters on the properties of IN 718 superalloy by three-dimensional printing. Mater Charact. 2008;59(12):1728-1735.

[39] Clayton J, Millington-Smith D, Armstrong B. The application of powder rheology in additive manufacturing. JOM. 2015;67(3):544-548.

[40] Amado KWA, Schmid M, Levy G. Advances in SLS powder characterization. Proceedings of Solid Freeform Fabrication Symposium 2011;22(January 2011). p. 438-452.

[41] Spierings AB, Voegtlin M, Bauer T, et al. Powder flowability characterisation methodology for powder-bed-based metal additive manufacturing. Prog Addit Manuf. 2016;1(1-2):9-20.

[42] Dvořáčková $K$, Rabiškovǎ $M$, Masteiková $R$, et al. Soluble filler as a dissolution profile modulator for slightly soluble drugs in matrix tablets. Drug Dev Ind Pharm. 2009;35(8):930-940.

[43] Saw HY, Davies CE, Paterson AHJ, et al. Correlation between powder flow properties measured by shear testing and Hausner ratio. Procedia Eng. 2015;102:218-225.

[44] Grey RO, Beddow JK. On the Hausner ratio and its relationship to some properties of metal powders. Powder Technol. 1969;2(6):323-326.

[45] Bai Y, Wagner G, Williams CB. Effect of bimodal powder mixture on powder packing density and sintered density in binder Jetting of metals. Annual 
International Solid Freeform Fabrication Symposium; 2015. p. 62.

[46] Roberts AW. Vibration of fine powders and its application. In: Fayed ME, editor. Handbook of Powder Science \& Technology. Boston (MA, USA): Springer US; 1997. p. 146-201.

[47] Gibson I, Rosen D, Stucker B. Additive manufacturing technologies: 3D printing, rapid prototyping, and direct digital manufacturing, Second Edition. 2015: 1-498.

[48] Haeri S, Wang Y, Ghita O, et al. Discrete element simulation and experimental study of powder spreading process in additive manufacturing. Powder Technol. 2017;306:45-54.

[49] Cao S, Qiu Y, Wei X-F, et al. Experimental and theoretical investigation on ultra-thin powder layering in three dimensional printing (3DP) by a novel double-smoothing mechanism. J Mater Process Tech. 2015;220:231-242.

[50] Meier C, Weissbach R, Weinberg J, et al. Modeling and characterization of cohesion in fine metal powders with a focus on additive manufacturing process simulations. Powder Technol. 2019;343:855-866.

[51] Sheydaeian E, Fishman Z, Vlasea M, et al. On the effect of throughout layer thickness variation on properties of additively manufactured cellular titanium structures. Addit Manuf. 2017;18:40-47.

[52] Miyanaji H, Zhang S, Lassell A, et al. Process development of porcelain ceramic material with binder jetting process for dental applications. JOM. 2016;68 (3):831-841.

[53] Miyanaji H, Zhang S, Lassell A, et al. Optimal process parameters for 3D printing of porcelain structures. Procedia Manuf. 2016;5:870-887.

[54] Miyanaji H, Orth M, Akbar JM, et al. Process development for green part printing using binder jetting additive manufacturing. Front Mech Eng. 2018;13 (4):504-512.

[55] Bai Y, Wagner G, Williams CB. Effect of particle size distribution on powder packing and sintering in binder Jetting additive manufacturing of metals. J Manuf Sci Eng. 2017;139(8):081019.

[56] Hsu TJ, Lai WH. Manufacturing parts optimization in the three-dimensional printing process by the Taguchi method. J Chinese Inst Eng Trans Chinese Inst Eng A/Chung-kuo K. Ch'eng Hsuch K'an. 2010;33(1):121-130.

[57] Shrestha S, Manogharan G. Optimization of binder jetting using Taguchi method. JOM. 2017;69 (3):491-497.

[58] Lee S-JJ. Powder Layer Generation for Three Dimensional Printing. Massachusetts Institute of Technology. 1992.

[59] Chen H, Zhao YF. Process parameters optimization for improving surface quality and manufacturing accuracy of binder jetting additive manufacturing process. Rapid Prototyp J. 2016;22(3):527-538.

[60] Gaytan SM, et al. Fabrication of barium titanate by binder jetting additive manufacturing technology. Ceram Int. 2015;41(5):6610-6619.

[61] Chen H. A process modelling and parameters optimization and recommendation system for binder jetting additive manufacturing process. McGill University; 2015 (Master Thesis).

[62] Miyanaji H, Zhang S, Yang L. A new physics-based model for equilibrium saturation determination in binder jetting additive manufacturing process. Int J Mach Tools Manuf. 2018;124(September 2017):1-11.

[63] Miyanaji H, Yang L. Equilibrium saturation in binder jetting additive manufacturing processes: theoretical model vs. experimental observations. In Solid Freeform Fabrication Symposium - Additive Manufacturing. 2016;I. p. 1945-1959.

[64] Oostveen MLM, Meesters GMH, van Ommen JR. Quantification of powder wetting by drop penetration time. Powder Technol. 2015;274:62-66.

[65] Hapgood KP, Litster JD, Biggs SR, et al. Drop penetration into porous powder beds. J Colloid Interface Sci. 2002;253(2):353-366.

[66] Nefzaoui E, Skurtys O. Impact of a liquid drop on a granular medium: inertia, viscosity and surface tension effects on the drop deformation. Exp Therm Fluid Sci. 2012;41:43-50.

[67] Tan H. Three-dimensional simulation of micrometersized droplet impact and penetration into the powder bed. Chem Eng Sci. 2016;153:93-107.

[68] Parab ND, Barnes JE, Zhao C, et al. Real time observation of binder jetting printing process using highspeed X-ray imaging. Sci Rep. 2499;9(28-30):2499.

[69] Tan MXL, Wong LS, Lum KH, et al. Foam and drop penetration kinetics into loosely packed powder beds. Chem Eng Sci. 2009;64(12):2826-2836.

[70] Miyanaji H, Momenzadeh N, Yang L. Effect of printing speed on quality of printed parts in binder jetting process. Addit Manuf. 2018;20:1-10.

[71] Wang Y, Zhao YF. Investigation of sintering shrinkage in binder Jetting additive manufacturing process. Procedia Manuf. 2017;10:779-790.

[72] Gardan J. Method for characterization and enhancement of 3D printing by binder jetting applied to the textures quality. Assem Autom. 2017;37(2):162-169.

[73] "Ethylene Glycol". [Online]. Available from: https:// antifreeze-science.weebly.com/pros-cons.html.

[74] Do T, Kwon P, Shin CS. Process development toward full-density stainless steel parts with binder jetting printing. Int J Mach Tools Manuf. 2017;121 (November 2016):50-60.

[75] Elliott A, AlSalihi S, Merriman AL, et al. Infiltration of nanoparticles into porous binder Jet printed parts. Am J Eng Appl Sci. 2016;9(1):128-133.

[76] Bailey A, Merriman A, Elliott A, et al. Preliminary testing of nanoparticle effectiveness in binder jetting applications. In 27th Annual International Solid Freeform Fabrication Symposium, 2016. p. 10691077.

[77] Sun L, Kim Y-H, Kim D-W, et al. Densification and properties of 420 stainless steel produced by threedimensional printing With addition of Si3N4 powder. J Manuf Sci Eng. 2009;131:061001.

[78] Cordero ZC, Siddel DH, Peter WH, et al. Strengthening of ferrous binder jet 3D printed components through bronze infiltration. Addit Manuf. 2017;15:87-92.

[79] Williams CB, Cochran JK, Rosen DW. Additive manufacturing of metallic cellular materials via threedimensional printing. Int J Adv Manuf Technol. 2011;53(1-4):231-239.

[80] Xiong Y, Qian C, Sun J. Fabrication of porous titanium implants by three-dimensional printing and sintering at different temperatures. Dent Mater J. 2012;31:815-820.

[81] Dilip JJS, Miyanaji H, Lassell A, et al. A novel method to fabricate TiAl intermetallic alloy $3 \mathrm{D}$ parts using 
additive manufacturing. Def Technol. 2017;13(2):7276.

[82] Mostafaei A, Stevens EL, Hughes ET, et al. Powder bed binder jet printed alloy 625: densification, microstructure and mechanical properties. Mater Des. 2016;108:126-135.

[83] Mostafaei A, Stevens EL, Ference JJ, et al. Binder jet printing of partial denture metal framework from metal powder. In: Materials Science and Technology Conference and Exhibition. 2017; Vol. 1, p. 289-291.

[84] Nandwana P, Elliott AM, Siddel D, et al. Powder bed binder jet 3D printing of Inconel 718: densification, microstructural evolution and challenges. Curr Opin Solid State Mater Sci. 2017;21:207-218.

[85] Bai Y, Williams CB. An exploration of binder jetting of copper. Rapid Prototyp J. 2015;21(2):177-185.

[86] Levy A, Miriyev A, Elliott A, et al. Additive manufacturing of complex-shaped graded TiC/steel composites. Mater Des. 2017;118:198-203.

[87] Fu Z, Schlier L, Travitzky N, et al. Three-dimensional printing of SiSiC lattice truss structures. Mater Sci Eng A. 2013;560:851-856.

[88] Mayara M, et al. Fabrication of Ti 3 SiC 2 -based composites via three-dimensional printing: influence of processing on the final properties. Ceram Int. 2016;42:9557-9564.

[89] Paranthaman MP, et al. Binder jetting: A novel $\mathrm{NdFeB}$ bonded magnet fabrication process. JOM. 2016;68(7):1978-1982.

[90] Li L, et al. A novel method combining additive manufacturing and alloy infiltration for $\mathrm{NdFeB}$ bonded magnet fabrication. J Magn Magn Mater. 2017;438:163-167.

[91] Rabinskiy L, Ripetsky A, Sitnikov S, et al. Fabrication of porous silicon nitride ceramics using binder jetting technology. IOP Conf Ser Mater Sci Eng. 2016;140:012023.

[92] Lu K, Hiser M, Wu W. Effect of particle size on three dimensional printed mesh structures. Powder Technol. 2008;192:178-183.

[93] Lu K, Reynolds WT. 3DP process for fine mesh structure printing. Powder Technol. 2008;187(1):11-18.

[94] Bai Y, Williams CB. Binderless jetting: additive manufacturing of metal parts via Jetting nanoparticles. International Solid Freeform Fabrication Symposium 2017. p. 249-260.

[95] Bai Y, Williams CB. Binder jetting additive manufacturing with a particle-free metal ink as a binder precursor. Mater Des. 2018;147:146-156.

[96] Zhao H, Ye C, Fan Z, et al. 3D printing of CaO-based ceramic core using nanozirconia suspension as a binder. J Eur Ceram Soc. 2017;37:5119-5125.

[97] Godlinski D, Morvan S. Steel parts with tailored material Gradients by 3D-printing using nano-particulate Ink. Mater Sci Forum. 2005;492-493:679684.

[98] Breu F, Guggenbichler S, Wollmann J. Three dimensional printing of Tungsten carbide-cobalt using a cobalt oxide precursor. Solid Freeform Fabrication Symposium. 2003;13:616-631.

[99] Bai Y, Wall C, Pham H, et al. Characterizing binderpowder interaction in binder Jetting additive manufacturing Via Sessile drop Goniometry. J Manuf Sci Eng Trans ASME. 2019;141(1):011005.

[100] German RM. Sintering theory and practice. WhileyVCH, 1996.
[101] Do T, et al. Improving structural integrity with boronbased additives for 3D printed 420 stainless steel. Procedia Manuf. 2015;1:263-272.

[102] Kim Y. Densification and properties evolution of stainless steel alloys fabricated by three-dimensional printing. Washington State University; 2009.

[103] Doyle M, Agarwal K, Sealy W, et al. Effect of layer thickness and orientation on mechanical behavior of binder Jet stainless steel $420+$ bronze parts. Procedia Manuf. 2015;1:251-262.

[104] Kumar A, Bai Y, Eklund A, et al. Effects of hot isostatic pressing on copper parts fabricated via binder jetting. Procedia Manuf. 2017;10:935-944.

[105] Yegyan Kumar A, Bai Y, Eklund A, et al. The effects of hot isostatic pressing on parts fabricated by binder jetting additive manufacturing. Addit Manuf. 2018;24:115-124.

[106] Sicre-Artalejo J, Petzoldt F, Campos M, et al. Highdensity inconel 718: three-dimensional printing coupled with hot isostatic pressing. Int J Powder Metall. 2008;44(1):35-43.

[107] Enneti RK, Prough KC, Wolfe TA, et al. Sintering of WC-12\%Co processed by binder jet 3D printing (BJ3DP) technology. Int J Refract Met Hard Mater. 2017 2017;71:28-35.

[108] Fayazfar H, et al. A critical review of powder-based additive manufacturing of ferrous alloys: process parameters, microstructure and mechanical properties. Mater Des. 2018;144:98-128.

[109] Verlee B, Dormal T, Lecomte-Beckers J. Density and porosity control of sintered 3161 stainless steel parts produced by additive manufacturing. Powder Metall. 2012;55(4):260-267.

[110] Ziaee M, Tridas EM, Crane NB. Binder-Jet printing of fine stainless steel powder with varied final density. JOM. 2017;69(3):592-596.

[111] Tang Y, Zhou Y, Hoff T, et al. Elastic modulus of 316 stainless steel lattice structure fabricated via binder jetting process. Mater Sci Technol. 2016;32(7):648656.

[112] Godlinski D, Veltl G. Three dimensional printing of PM-tool steels. Euro PM2005. 2005;3:49-54.

[113] Zhang B, Zhan Z, Cao Y, et al. Metallic 3-D printed antennas for millimeter- and submillimeter wave applications. IEEE Trans Terahertz Sci Technol. 2016;6(4):592-600.

[114] Mostafaei A, Behnamian Y, Krimer YL, et al. Effect of solutionizing and aging on the microstructure and mechanical properties of powder bed binder jet printed nickel-based superalloy 625. Mater Des. 2016;111:482-491.

[115] Mostafaei A, Behnamian Y, Krimer YL, et al. Brief data overview of differently heat treated binder jet printed samples made from argon atomized alloy 625 powder. Data Br. 2016;9:556-562.

[116] Mostafaei A, Neelapu SHVR, Kisailus C, et al. Characterizing surface finish and fatigue behavior in binder-jet 3D-printed nickel-based superalloy 625 . Addit Manuf. 2018;24:200-209.

[117] Rahaman MN. Ceramic processing and sintering. CRC Press; 2003.

[118] Liu Y, Tandon R, German RM. Modeling of supersolidus liquid phase sintering: I. Capillary force. Metall Mater Trans A. 1995;26(9):2415-2422.

[119] Liu Y, Tandon R, German RM. Modeling of supersolidus liquid phase sintering: II. Densification. Metall Mater Trans A. 1995;26(9):2423-2430. 
[120] Sheydaeian E, Toyserkani E. A new approach for fabrication of titanium-titanium boride periodic composite via additive manufacturing and pressure-less sintering. Compos Part B Eng. 2018;138:140-148.

[121] Wu X. Review of alloy and process development of TiAl alloys. Intermetallics. 2006;14(10-11):11141122.

[122] Stevens E, Schloder S, Bono E, et al. Density variation in binder jetting 3D-printed and sintered Ti-6Al-4V. Addit Manuf. 2018;22(May):746-752.

[123] Snelling DA, Williams CB, Suchicital CTA, et al. Binder jetting advanced ceramics for metal-ceramic composite structures. Int J Adv Manuf Technol. 2017;92(1-4):531-545.

[124] Halbig MC, Singh M. Additive manufacturing of SiCbased ceramics and ceramic matrix composites. 11th International Conference on Ceramic Materials and components for energy and environmental Applications; Vancouver, Canada, 2015.

[125] Li L, Post B, Kunc V, et al. Additive manufacturing of near-net-shape bonded magnets: Prospects and challenges. Scr Mater. 2017;135:100-104.

[126] Frazier WE. Metal additive manufacturing: a review. ASM Int. 2014. 